\title{
Bordetella pertussis in School-Age Children, Adolescents, and Adults: A Systematic Review of Epidemiology, Burden, and Mortality in Asia
}

\author{
Denis Macina $\cdot$ Keith E. Evans
}

Received: January 29, 2021 / Accepted: March 24, 2021 / Published online: April 29, 2021

(C) The Author(s) 2021

\begin{abstract}
Cyclic epidemics of pertussis (whooping cough) have been observed globally over the past twenty years despite high infant vaccine coverage. The resurgence of pertussis in high-income countries is partly due to waning vaccine immunity in older children and adults, as well as better surveillance and diagnostics. Moreover, in adolescents and adults, pertussis symptoms are mild and similar to common cough syndromes, meaning that it is under-diagnosed in older populations. A systematic search of MEDLINE, EMBASE, and BIOSIS was undertaken to identify studies published between 1 January 1990 and 17 June 2019, with information on pertussis epidemiology, burden of illness, and mortality in school-aged children, adolescents, and adults in Asia. Studies identified for inclusion were reviewed narratively because a statistical comparison was not possible due to the mix of methodologies used.
\end{abstract}

Supplementary Information The online version contains supplementary material available at https:// doi.org/10.1007/s40121-021-00439-1.

D. Macina $(\bowtie)$

Global Medical, Sanofi Pasteur, 14 Espace Henry

Vallée, 69007 Lyon, France

e-mail: Denis.Macina@sanofi.com

K. E. Evans

InScience Communications, Chowley Oak Business

Park, Chowley Oak Lane, Tattenhall, Cheshire, UK
The results showed that in East Asia, including Japan, South Korea, China, and Taiwan, pertussis is circulating in older children and adults. Diphtheria-tetanus-pertussis (DTP4) coverage is high in East Asia, yet outbreaks observed in Japan and South Korea suggest that vaccine-acquired immunity had waned in adolescents and adults. Several school outbreaks in China show that pertussis is circulating in young children, with continued circulation in adolescents and adults. There was a lack of information from Southeast/South Asian countries, although panAsian serosurveys showed that recent pertussis infection was common in adolescents and in adults with persistent cough. To conclude, the circulation of pertussis in Asian countries with high DTP4 coverage supports the expansion of routine vaccination to include booster doses for children at school entry and adolescents. However, surveillance is weak or absent in many countries, meaning that the true burden of pertussis, particularly among older populations, is unknown.

Keywords: Adolescents; Adults; Asia; Burden; Children; Epidemiology; Pertussis; Whooping cough 


\section{Key Summary Points}

A systematic search was undertaken to identify published studies with information on pertussis epidemiology, burden of illness, and mortality in schoolaged children, adolescents, and adults in Asia.

Forty seven studies were included.

The results showed that in East Asia, including Japan, South Korea, China, and Taiwan, pertussis is circulating in older children and adults.

Several school outbreaks in China show that pertussis is circulating in young children, with continued circulation in adolescents and adults. There was a lack of information from Southeast/South Asian countries, although pan-Asian serosurveys showed that recent pertussis infection was common in adolescents and in adults with persistent cough.

Surveillance is weak or absent in many countries, meaning that the true burden of pertussis, particularly among older populations, is unknown.

\section{DIGITAL FEATURES}

This article is published with digital features, including a summary slide, to facilitate understanding of the article. To view digital features for this article go to https://doi.org/10.6084/ m9.figshare.14261357.

\section{INTRODUCTION}

Bordetella pertussis is a highly contagious gramnegative bacterium that infects the respiratory tract and causes severe coughing (whooping cough). Vaccination against pertussis began in the 1950s and the use of modern-day vaccines

and global immunization efforts have resulted in a large reduction in pertussis-related childhood mortality [1]. Vaccine coverage of three doses of diphtheria-tetanus-pertussis vaccine in the first year of life (DTP3) is $85-86 \%$ in most countries, and numerous countries include a pre-school booster and an adolescent booster in their national immunization programmes (NIPs) [2]. Yet despite high vaccine coverage, pertussis persists globally with cyclical epidemics every $3-4$ years [3].

Pertussis can be severe in infants and is associated with substantial morbidity, yet in adolescents and adults, pertussis usually manifests as a mild respiratory illness meaning that it is largely under-recognized in adults [1]. Moreover, studies among highly vaccinated populations show that vaccine immunity wanes, resulting in a pool of unprotected adults, providing a reservoir for infection [4-6]. In several high-income countries with high childhood vaccination coverage, the age-specific peak of notified pertussis cases has shifted away from infants and pre-school children and towards adolescents and adults [7, 8]. Reasons for the increased prevalence of pertussis observed among older populations include, in addition to the waning of vaccine-acquired immunity, improved surveillance and awareness of pertussis among adults, and improved diagnostics [3]. Vaccine-driven evolution of B.pertussis strains that do not express pertactin is another factor that could contribute pertussis epidemics [9-11]. In several countries with high vaccine coverage, pertactin-deficient strains have been reported, including Australia where the proportion of isolates that were pertactin deficient increased from more than $10 \%$ to approximately 80\% between 2008 and 2012 [9, 10, 12].

Nearly $60 \%$ of the global population lives in Asia, with China and India alone comprising $36 \%$ of the total [13]. In a global modelling study, it was estimated that in Southeast Asia in $2014,3.5 \%$ of children aged $<5$ years were infected with pertussis, equating to 6.3 million cases and 42,500 deaths [14]. The World Health Organization (WHO) estimates among children aged $<5$ years in Southeast Asia, including Bangladesh, India, Indonesia, and Thailand, show that over the past 5 years, after measles, 
diphtheria, and mumps, pertussis was the most frequently reported vaccine-preventable disease, with cyclical peaks; the highest number of cases was in $2016(43,141)$ and the lowest was in 2019 (12,052) [15]. WHO estimates of childhood diseases in the Asia-Pacific region include high-income countries such as Australia, New Zealand, and Japan, as well as several low- and middle-income countries (LMICs) such as Malaysia, China, Cambodia, and Vietnam [16]. Among children aged $<5$ years in the Asia-Pacific region, apart from 2019, when measles and pertussis were the most frequent vaccine-preventable diseases, in the past 5 years, mumps was the most prevalent vaccine-preventable disease, followed by pertussis and measles, as second and third, depending on the year. The highest number of pertussis cases in the past 5 years in the Asia-Pacific region were reported in $2019(63,483)$ and the lowest year for cases was $2017(27,624)$ [16]. Surveillance systems are weak in some Asian countries, yet available data show that the burden of pertussis in infants and young children is high in Asian countries [17]. However, much less is known about the prevalence of pertussis in older children and adults, and the role of this population in the transmission of pertussis across Asia.

This systematic literature search and review of published studies was performed to assess the epidemiology, burden, and mortality of pertussis infection among school-aged children, adolescents, and adults in Asia.

\section{METHODS}

A systematic research of the literature was conducted using EMBASE, MEDLINE, and BIOSIS, on 17 June 2019 to identify articles about the global epidemiology of pertussis and the burden of disease such as morbidity and mortality, healthcare usage, and hospitalization.

Citations were limited to those in English language, in humans, and published since 1 January 1990. Terms used in the database searches are shown in Supplement 1 in the Supplementary Material. Web searches were also performed to identify relevant data from governmental, national or regulatory websites, and from non-government organisations (Supplement 2).

The areas of interest were epidemiology and sero-epidemiology, clinical burden, and pertussis-related mortality and case fatality rates (CFRs). Papers were excluded if they contained no data of relevance (e.g. not a pertussis study); no data which could be categorised by age groups; a study of pertussis vaccination (e.g. adverse events related to the vaccine); single subject design (e.g. case studies); contained no primary data (in these cases, reference lists were checked and potentially useful papers not identified in the original search were obtained for assessment); and based on a model (either economic or epidemiological), which included no epidemiology source for the calculations or were based on a publication already included in the search.

The review included publications with data for school-aged children, adolescents, and adults. The objective was to review the epidemiology, burden, and mortality of pertussis by age: young children (aged 4-9 years); adolescents (aged 10-18 years), adults (aged $\geq 19$ years), and older adults (aged $\geq 60$ years).

A total of 2190 citations were identified for the global review of epidemiology and burden. Following an initial review, 763 papers (35\% of the original search) were obtained for full assessment of the inclusion criteria. The search results and reasons for exclusion are shown in Supplement 3. A total of 1421 citations were identified for the global review of mortality. Following an initial review, 331 papers (23\% of the original search) were obtained for full assessment of the inclusion criteria. The search results and reasons for exclusion are shown in Supplement 4.

The systematic review was conducted to assess pertussis globally, and the results for Europe, the Middle East, and Africa, are provided as parallel publications. This paper provides the results of articles identified with relevant data from countries in Asia.

There was a wide variation in the methods used to assess the epidemiology and sero-epidemiology of pertussis regarding national reporting rules, surveillance methods, clinical 
diagnostic criteria, laboratory tests, antibody cut-off values, and reporting years, i.e. epidemic and interepidemic. The differences between studies meant that it was not possible to perform any formal analyses (e.g. meta-analysis) using combined data from multiple studies for any parameter, so a narrative review was performed.

\section{Compliance with Ethics Guidelines}

This article is based on previously conducted studies and does not contain any new studies with human participants or animals performed by any of the authors.

\section{SEARCH RESULTS}

There were 12 studies of epidemiology in Asia covering China [18-20], Taiwan [21, 22], Japan [23-26], South Korea [27, 28], and India [29]. There were 37 studies of sero-epidemiology in Asia covering China [18-20, 30-39], Taiwan $[21,22,40-42]$, Singapore [43, 44], Japan [23-26, 45-49], South Korea [28, 50-53], Thailand [54], and multiple countries [55, 56].

There were five studies about burden in Japan [57-61], four in South Korea [28, 62-64], one in India [29], and one which included three Asian countries (Taiwan, Malaysia, and Thailand) [55].

There were no studies with mortality data specifically for the populations considered in the review.

\section{Serological Thresholds for Infection}

Polymerase chain reaction (PCR) and culture can be used to diagnose pertussis, although serology of IgG-based enzyme-linked immunosorbent assays (ELISAs) is the laboratory method that is used routinely. An International consensus meeting in 2007, recommended that pertussis toxin (PT) should be used as antigen and that the results should be expressed in international units (IU/ml) using WHO international standards $[65,66]$. Whereas a fourfold increase in anti-PT immunoglobulin $G \quad$ (IgG) agglutinin titers between samples is accepted as evidence of recent infection, there is currently no global consensus on cut-off thresholds for single-sample serology.

The thresholds for anti-PT IgG seropositivity are usually defined on the basis of the manufacturer's instructions for the ELISA test, as well as previous experience [67-69]. In individuals who have not been vaccinated within 1 year of the serum sample, anti-PT IgG $\geq 62.5$ to $\geq 80 \mathrm{IU} / \mathrm{ml}$, are often used as the cut-off thresholds indicating pertussis infection within 12 months, and cut-offs of $\geq 100 \mathrm{IU} / \mathrm{ml}$ and $\geq 125 \mathrm{IU} / \mathrm{ml}$ as evidence of recent infection and acute infection, respectively [66, 70, 71]. However, using data from three separate studies in Europe, receiver operator curves showed that the cut-off threshold with optimal sensitivity and specificity may be in the range between 60 and $75 \mathrm{IU} / \mathrm{ml}$ [67].

Various serological thresholds were used in the studies identified for review. In the pan-Asia studies, the anti-PT IgG cut-offs were $\geq 62.5 \mathrm{IU} /$ $\mathrm{ml}$ and $\geq 100 \mathrm{IU} / \mathrm{ml}$, and in Japan, the majority of studies defined the cut-off for pertussis infection as anti-PT IgG $\geq 100 \mathrm{IU} / \mathrm{ml}$. In China, the majority of studies defined recent infection as anti-PT IgG $\geq 80$ or $\geq 100 \mathrm{IU} / \mathrm{ml}$, one study as anti-PT IgG $\geq 62.5 \mathrm{IU} / \mathrm{ml}$, and several studies used lower thresholds, ranging from anti-PT $\operatorname{IgG} \geq 16$ to $\geq 40 \mathrm{IU} / \mathrm{ml}$. Several studies used ELISA yet did not state the cut-off value, and some studies diagnosed pertussis using PCR and/or culture.

\section{EAST ASIA}

Most of the articles identified for review were from East Asia, including Japan (Table 1), China (Table 2), Taiwan, and South Korea (Table 3).

\section{Japan}

The vaccination schedule in Japan includes DTP at $3,5,6$, and 18 months, yet the routine national immunization program (NIP) does not currently include boosters for adolescents, pregnant women, and adults [72, 73]. 
Table 1 Overview of studies of pertussis in children and adults in Japan (by publication date)

\begin{tabular}{|c|c|c|c|c|}
\hline Citation & Design, period & $\begin{array}{l}\text { Age, } n \text {, sample } \\
\text { type }\end{array}$ & Test and serological cut-off value & Key findings \\
\hline$[45]$ & $\begin{array}{l}\text { Retrospective, } \\
\text { National Serum } \\
\text { Reference Bank } \\
\text { surveillance } \\
2015 \text { to } 2016\end{array}$ & $\begin{array}{l}1-60 \text { years } \\
460 \text { random } \\
\text { sample }\end{array}$ & $\begin{array}{l}\text { PT IgA seropositive } \\
\text { PT IgM seropositive }\end{array}$ & $\begin{array}{l}17.6 \%, 46-50 \text { years } \\
39.5 \%, 11-15 \text { years }\end{array}$ \\
\hline [23] & $\begin{array}{l}\text { Retrospective, } \\
\text { national } \\
\text { pertussis } \\
\text { surveillance } \\
2000 \text { to } 2016\end{array}$ & $\begin{array}{l}\text { All ages } \\
\text { Population }\end{array}$ & $\begin{array}{l}\text { Sentinel data } \\
\text { Diagnostic criteria not stated }\end{array}$ & $\begin{array}{l}\text { Pertussis prevalence } \\
\text { 2001: } 27 \% \text { aged } 6-11 \text { months; } 3 \% \\
\text { aged } \geq 20 \text { years } \\
\text { 2010: } 48 \% \text { aged } \geq 20 \text { years; } 4 \% \\
\text { aged 6-11 months } \\
\text { 2000-2015: } 48,783 \text { cases }\end{array}$ \\
\hline$[47]$ & $\begin{array}{l}\text { Prospective, } \\
\text { population- } \\
\text { based } \\
2013 \text { and } 2014\end{array}$ & $\begin{array}{l}12-13 \text { years } \\
3243 \text { random } \\
\text { paired sample }\end{array}$ & $\begin{array}{l}\text { PT } \operatorname{IgG} \geq 100 \mathrm{EU} / \mathrm{ml} \\
\text { PT } \mathrm{IgG} \geq 100 \mathrm{EU} / \mathrm{ml}\end{array}$ & $\begin{array}{l}\text { 2013: } 4.4 \% \\
\text { 2014: } 3.7 \%\end{array}$ \\
\hline [24] & $\begin{array}{l}\text { Retrospective, } \\
\text { outbreak } \\
\text { surveillance } \\
\text { (outpatient } \\
\text { facility) } \\
\text { October } 2013 \text { to } \\
\text { April } 2014\end{array}$ & $\begin{array}{l}\text { Adults } \\
19 \\
\text { haemodialysis } \\
\text { patients } \\
19 \text { HCW }\end{array}$ & $\begin{array}{l}\text { Highly positive: PT } \\
\text { IgG } \geq 100 \mathrm{EU} / \mathrm{ml} \\
\text { Positive PT IgG: } 10-100 \mathrm{EU} / \mathrm{ml} \\
\text { Negative PT IgG: }<10 \mathrm{EU} / \mathrm{ml}\end{array}$ & $\begin{array}{l}n=0 \\
n=16 \\
n=22\end{array}$ \\
\hline$[60]$ & $\begin{array}{l}\text { Retrospective, } \\
\text { outbreak } \\
\text { surveillance } \\
\text { (university) } \\
\text { April } 2010\end{array}$ & $\begin{array}{l}\text { Young adults } \\
636 \text { students }\end{array}$ & $\mathrm{PT} \mathrm{IgG}>100 \mathrm{EU} / \mathrm{ml}$ & $\begin{array}{l}245 \text { persistent cough } \\
84 / 636 \text { 'probable' infection }(13.2 \%) \\
24 / 636(3.7 \%)\end{array}$ \\
\hline [59] & $\begin{array}{l}\text { Retrospective, } \\
\text { case surveillance } \\
\text { Circa } 2013\end{array}$ & $\begin{array}{l}\text { Adults } \\
48 \text { confirmed } \\
\text { cases } \\
20 \text { controls }\end{array}$ & $\begin{array}{l}\text { PT IgG }>100 \mathrm{IU} / \mathrm{ml} \\
\text { or } \\
\text { twofold change in PT IgG }\end{array}$ & $\begin{array}{l}\text { Duration of cough at first visit } \\
1.21 \pm 1.33 \text { months (vs control } \\
p=0.0262 \text { ) } \\
\text { All duration of cough } \\
2.03 \pm 1.25 \text { months (vs control } \\
0.049 \text { ) } \\
\text { Paroxysmal cough } 47.8 \% \text { (vs control } \\
0.0485 \text { ) } \\
\text { Post-tussive vomiting } 30.4 \% \text { (vs } \\
\text { control } 0.999 \text { ) }\end{array}$ \\
\hline
\end{tabular}


Table 1 continued

\begin{tabular}{|c|c|c|c|c|}
\hline Citation & Design, period & $\begin{array}{l}\text { Age, } n \text {, sample } \\
\text { type }\end{array}$ & Test and serological cut-off value & Key findings \\
\hline [48] & $\begin{array}{l}\text { Prospective, } \\
\text { outbreak } \\
\text { surveillance } \\
\text { (workplace) } \\
\text { May-June } 2010\end{array}$ & $\begin{array}{l}21-56 \text { years } \\
4 \text { staff } 5 \\
\text { household } \\
\text { contact } \\
\text { suspected } \\
\text { cases }\end{array}$ & $\begin{array}{l}\text { PT } \operatorname{IgG}>100 \mathrm{EU} / \mathrm{ml} \\
\text { Antibody titer } \geq 1: 320 \text { for } \\
\quad \text { Yamaguchi strain }\end{array}$ & $\begin{array}{l}\text { Pertussis infection } 7 / 9 \\
4 \text { showed seroconversion against } \\
\text { Yamaguchi strain }\end{array}$ \\
\hline [61] & $\begin{array}{l}\text { Prospective, } \\
\text { outbreak } \\
\text { surveillance } \\
\text { (university) } \\
2007\end{array}$ & $\begin{array}{l}\text { Adults } \\
361 \text { students } \\
\text { and staff with } \\
\text { cough }\end{array}$ & $\begin{array}{l}\text { Agglutination antibody titer } \geq 40 \text { - } \\
\text { fold increase }\end{array}$ & $\begin{array}{l}\text { Antibody levels significantly } \\
\text { different }(p<0.001) \text { between } \\
\text { healthy people and patients for } \\
\text { Yamaguchi strain but not } \\
\text { Tohama strain }\end{array}$ \\
\hline$[58]$ & $\begin{array}{l}\text { Prospective, } \\
\text { hospital-based, } \\
\text { case surveillance } \\
\text { March } 2009\end{array}$ & $\begin{array}{l}\geq 20 \text { years } \\
316 \text { clinical } \\
\text { cases }\end{array}$ & Cut-off not stated & $\begin{array}{l}26 \text { confirmed cases aged } 23-78 \text { years } \\
68 \% \text { long-lasting cough } \\
69.2 \% \text { night cough } \\
54 \% \text { paroxysmal cough } \\
19 \% \text { vomiting } 19 \% \\
7.7 \% \text { whooping } 7.7 \%\end{array}$ \\
\hline$[46]$ & $\begin{array}{l}\text { Prospective, } \\
\text { medical staff } \\
\text { Circa } 2008\end{array}$ & $\begin{array}{l}25-58 \text { years } \\
48 \text { doctors and } \\
\text { nurses }\end{array}$ & $\begin{array}{l}\text { Agglutination antibody titer } \geq 40 \text { - } \\
\text { fold increase } \\
\text { FHA } \mathrm{IgG} \geq 10 \mathrm{EU} / \mathrm{ml} \\
\text { PT } \mathrm{IgG} \geq 10 \mathrm{EU} / \mathrm{ml}\end{array}$ & $\begin{array}{l}81.3 \% \text { (Tohama strain); } 71.9 \% \\
\quad \quad \text { (Yamaguchi strain) } \\
68.8 \% \\
43.8 \%\end{array}$ \\
\hline [49] & $\begin{array}{l}\text { Retrospective, } \\
\text { hospital-based } \\
\text { January to May } \\
1996\end{array}$ & $\begin{array}{l}0-80 \text { years } \\
320 \text { random } \\
\text { sample }\end{array}$ & $\mathrm{PT} \operatorname{IgG} \geq 10 \mathrm{EU} / \mathrm{ml}$ & $\begin{array}{l}\text { Three age-specific peaks: aged } \\
11-15 \text { years, aged } 46-50 \text { years, } \\
\text { and aged } 56-60 \text { years }\end{array}$ \\
\hline$[25]$ & $\begin{array}{l}\text { Prospective, } \\
\text { hospital-based, } \\
\text { case surveillance } \\
\text { November } 1986 \\
\text { to October } 1992\end{array}$ & $\begin{array}{l}\text { All ages } \\
1521 \text { LRTI }\end{array}$ & $\begin{array}{l}>\text { fourfold increase in titers on } \\
\text { agglutination test between the } \\
\text { acute and convalescent phase } \\
\text { sera }\end{array}$ & $43.9 \%$ (668) confirmed cases \\
\hline
\end{tabular}


Table 1 continued

\begin{tabular}{|c|c|c|c|c|}
\hline$\overline{\text { Citation }}$ & Design, period & $\begin{array}{l}\text { Age, } n \text {, sample } \\
\text { type }\end{array}$ & Test and serological cut-off value & Key findings \\
\hline$[57]$ & $\begin{array}{l}\text { Prospective, } \\
\text { outbreak } \\
\text { surveillance } \\
\text { (school) } \\
\text { May to August } \\
1987\end{array}$ & $\begin{array}{l}11-12 \text { years } \\
43 / 38 \text { (full class } \\
\text { or vaccinated) }\end{array}$ & $\begin{array}{l}\text { Fourfold increase in titers of } \\
\text { paired sera from one of PT IgG, } \\
\text { FHA IgG, or agglutination test }\end{array}$ & $\begin{array}{l}\text { Attack rate } 7 / 38(18.4 \%) \\
8 \text { with paroxysmal coughing for } \\
>3 \text { weeks }\end{array}$ \\
\hline$[26]$ & $\begin{array}{l}\text { Prospective, } \\
\text { outbreak } \\
\text { surveillance } \\
\text { (care facility) } \\
\text { December } 1989\end{array}$ & $\begin{array}{l}8-25 \text { years } \\
50 \text { residents } \\
43 \text { carers }\end{array}$ & $\begin{array}{l}\text { Positive culture, or fourfold } \\
\text { increase in PT IgG, FHA IgG, } \\
\text { or agglutination antibody titer } \\
\text { in paired sera, or PT } \\
\operatorname{IgG} \geq 10 \mathrm{EU} / \mathrm{ml}, \mathrm{FHA} \\
\operatorname{IgG} \geq 20 \mathrm{EU} / \mathrm{ml} \text {, or } \\
\text { agglutination antibody titer } \\
\geq 160 \text {-fold }\end{array}$ & $\begin{array}{l}\text { Residents } \\
82 \%(41) \text { serological evidence of } \\
\text { infection } \\
56 \%(28) \text { developed symptoms } \\
\text { Carers } \\
14 \%(6) \text { developed symptoms, } 4 / 6 \\
\text { had serological evidence of } \\
\text { infection }\end{array}$ \\
\hline
\end{tabular}

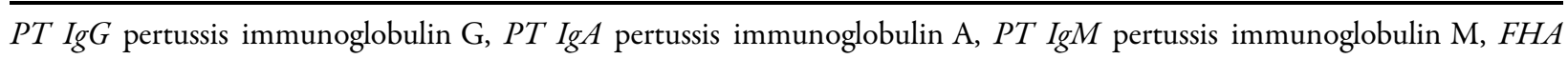
anti-filamentous haemagglutinin, $L R T I$ lower respiratory tract infection

DTP4 coverage in Japan is more than 98\%; however, between 1975 and 1981, wP was not used in Japan because of adverse neurological effects, and although an aP vaccine was introduced, many Japanese adults born during 1975-1981 did not receive vaccination [24].

Until 2017, the National Epidemiological Surveillance of Infectious Diseases in Japan monitored pertussis through paediatric sentinel sites, but because this did not represent the entire population, in 2018, the Infectious Disease Control Law was revised to include pertussis as a notifiable disease requiring laboratory-confirmed diagnosis [45].

\section{Active Surveillance}

In a study of an outbreak in an outpatient healthcare facility between October 2013 and January 2014, among 19 haemodialysis patients and 19 associated healthcare workers (HCWs), the prevalence rate was $42 \%$ among ELISA- confirmed cases [24]. In another study of HCWs on a ward with a suspected pertussis outbreak in 2007, among 48 HCWs with a mean age of 33 years, the rates of bacterial agglutination antibody positivity rates against the vaccine strains Tohama and Yamaguchi were $81.3 \%$ and $72.9 \%$, respectively, and levels of anti-PT and anti-FHA IgG (both $\geq 10$ endotoxin units [EU]/ $\mathrm{mL}$ ) were $43.8 \%$ and $68.8 \%$, respectively [46].

In an analysis of paired serum samples from 3243 Japanese junior and senior high school students collected in 2013 and 2014, the average decrease in anti-PT IgG levels was 35\% between the 2 years [47]. In the 2 years, respectively, $4.4 \%$ and $3.7 \%$ of the students had antiPT IgG levels of $\geq 100 \mathrm{EU} / \mathrm{ml}$. The local foci of at least fourfold anti-PT IgG increase in specific schools suggested that pertussis circulation persists in Japanese adolescents [47].

In a retrospective analysis of an outbreak at a university in Japan in 2010, among 636 
students, 245 students (mean age 20.4 years) reported persistent cough, of which 84 (13.2\%) were diagnosed as 'probable' cases based on clinical criteria [60]. The duration of cough was commonly more than 2 weeks, and the most common symptoms were paroxysmal cough, followed by post-tussive vomiting. Among the 245 students with continuous cough, 121 visited a healthcare provider, and 56 were diagnosed with pertussis by a physician. Among students who had received four doses of DTaP, the attack rate of 'probable' infection was $13.8 \%$ compared with $33 \%$ among unvaccinated students, and a significantly higher proportion of unvaccinated than vaccinated students reported coughing paroxysms. However, the seroprevalence of anti-PT IgG levels $\geq 100 \mathrm{EU} / \mathrm{ml}$ after the outbreak was similar in unvaccinated and vaccinated students [60].

\section{Passive Surveillance}

In the most recent sentinel surveillance study in Japan, between 2000 and 2015 there were 48,783 notified cases, and over time, there was a change in the age-specific proportion of cases [23]. In 2001, 27\% $(n=471)$ of the cases were aged 6-11 months and 3\% $(n=49)$ were aged $\geq 20$ years, yet by 2010, those aged $\geq 20$ years accounted for $48 \%(n=2607)$ of cases and those 6-11 months for $4 \%$ $(n=205)$ [23].

When the Infectious Disease Control Law in Japan was revised to include a laboratory-confirmed diagnosis, a seroprevalence study was conducted to assess serodiagnostic tests for PT immunoglobulin A (IgA) and PT immunoglobulin $\mathrm{M}$ (IgM). A seroprevalence study was conducted to assess serodiagnostic tests for PT IgA and PT IgM using serum samples from a crosssection of healthy Japanese people collected between 2015 and 2016 [45]. The analysis of age-specific distribution showed that the highest anti-PT IgA levels were observed in adults aged $46-50$ years $(6.0 \pm 6.3$ NovaTec test units [NTU]), and the highest anti-PT IgM levels were found in school children aged 11-15 years $(7.9 \pm 3.2 \mathrm{NTU})$. A total of $17.6 \%$ of people aged 46-50 years were seropositive ( $>11.5$ NTU) for anti-PT IgA. Anti-PT IgA levels increased with age, and there was a significant correlation between anti-PT IgA and anti-PT IgG in adults aged $41-45$ years $(p<0.001)$ [45]. The authors' concluded that the IgA and IgM assays had low diagnostic accuracy, with weak correlations with anti-PT IgG and anti-FHA IgG. The low specificity, particularly with the anti-PT IgM kit, and the arbitrary cut-offs with no thresholds for recent infection versus vaccination, means that the assays are of limited value for pertussis diagnosis [45].

\section{China}

Diphtheria toxoid combined with tetanus and whole-cell pertussis vaccines (DTwP) was introduced in China in 1978, and was replaced with diphtheria toxoid combined with tetanus and acellular pertussis vaccines (DTaP) in 2007 $[74,75]$. The NIP in China currently mandates DTP at 3,4 , and 5 months, and at 18-24 months. There are limited data on DTP4 coverage in China, yet surveillance studies in urban populations report coverage of about 95\% [19, 36].

China has a large national surveillance system to monitor 39 notifiable diseases, with all hospitals and clinics obliged to report suspected and confirmed cases to the local Center for Disease Control (CDC) [76]. The data are collected on the National Infectious Diseases Monitoring Information System Database, which was established in 2004 [76].

\section{Children and Adolescents}

In a school outbreak in China in 2015, among 383 students (aged 7-13 years) and 27 teachers in ten classes, the rate of laboratory-confirmed pertussis (PT IgG $\geq 80 \mathrm{IU} / \mathrm{ml}$ ) among students was $30.29 \%$ and among teachers was $7.41 \%$ [19]. In students in one class, the attack rate was $68.42 \%$ (26 cases), and ranged from $7.89 \%$ to $57.5 \%$ in the other classes. All of the students had received DTaP4 or DTwP4, and those who had received the last dose more than 4 years ago versus within 4 years were three times more likely to become ill with pertussis $(p=0.006)$. The pertussis attack rates were not significantly different between students who had received aP or $\mathrm{wP}$ vaccine [19]. In another school outbreak 
Table 2 Overview of studies of pertussis in children and adults in China (by publication date)

\begin{tabular}{|c|c|c|c|c|}
\hline Country & Design, period & $\begin{array}{l}\text { Age, } n \text {, sample } \\
\text { type }\end{array}$ & $\begin{array}{l}\text { Test and serological cut-off } \\
\text { value }\end{array}$ & Key findings \\
\hline$[122]$ & $\begin{array}{l}\text { Prospective, } \\
\text { hospital-based, } \\
\text { case surveillance } \\
\text { Jan } 2016 \text { to May } \\
2017\end{array}$ & $\begin{array}{l}1 \text { month to } 11 \\
\text { years } \\
312 \text { suspected } \\
\text { cases }\end{array}$ & $\mathrm{PT} \mathrm{IgG} \geq 62.5 \mathrm{IU} / \mathrm{ml}$ & $97(31.1 \%)$ \\
\hline$[35]$ & $\begin{array}{l}\text { Prospective, } \\
\text { population- } \\
\text { based } \\
2009-2017\end{array}$ & $\begin{array}{l}\text { All ages } \\
3360 \text { random } \\
\text { sample }\end{array}$ & PT IgG $\geq 16 \mathrm{EU} / \mathrm{ml}$ & $69.9 \%(95 \%$ CI $68.3-71.5)$ \\
\hline$[36]$ & $\begin{array}{l}\text { Prospective/ } \\
\text { retrospective, } \\
\text { population- } \\
\text { based } \\
\text { October to } \\
\text { November } 2015\end{array}$ & $\begin{array}{l}1-59 \text { years } \\
1080 \text { healthy } \\
\text { people }\end{array}$ & $\mathrm{PT}$ IgG $>100 \mathrm{IU} / \mathrm{ml}$ & $\begin{array}{l}1.17 \%(11 / 944) \\
\text { Incidence: } 7290 / 100,000 \\
\text { Peaks: aged } 7-14 \text { years }(9971 / 100,000) \\
\text { and } \geq 20 \text { years }(13,898 / 100,000)\end{array}$ \\
\hline [19] & $\begin{array}{l}\text { Prospective, } \\
\text { school cohort } \\
\text { (outbreak) } \\
\text { May to July } 2015\end{array}$ & $\begin{array}{l}\text { School children } \\
\text { and teachers } \\
383 \text { students, } 27 \\
\text { teachers }\end{array}$ & $\mathrm{PT} \operatorname{IgG} \geq 80 \mathrm{IU} / \mathrm{ml}$ & $\begin{array}{l}116(30.29 \%) \text { students } \\
2 \text { teachers }\end{array}$ \\
\hline$[20]$ & $\begin{array}{l}\text { Prospective, } \\
\text { school cohort } \\
\text { (outbreak) } \\
\text { March } 2016\end{array}$ & $\begin{array}{l}6-12 \text { years } \\
94 \text { suspected } \\
\text { cases }\end{array}$ & $\begin{array}{l}\text { PCR positive for IS } 481 \text { and/ } \\
\text { or ptxS1 but negative for } \\
\text { hIS } 1001 \text { and pIS } 1001\end{array}$ & 17 confirmed cases \\
\hline$[30]$ & $\begin{array}{l}\text { Prospective, } \\
\text { population- } \\
\text { based } \\
\text { May to December } \\
2010\end{array}$ & $\begin{array}{l}20-39 \text { years } \\
837 \text { random } \\
\text { sample }\end{array}$ & $\begin{array}{l}\text { PT IgG undetectable } \\
\text { PT IgG } \geq 40 \mathrm{IU} / \mathrm{ml} \\
\text { PT } \operatorname{IgG} \geq 100 \mathrm{IU} / \mathrm{ml}\end{array}$ & $\begin{array}{l}124(13 \%) \\
46(5.1 \%) \\
9(1 \%)\end{array}$ \\
\hline$[31]$ & $\begin{array}{l}\text { Prospective, } \\
\text { population- } \\
\text { based }\end{array}$ & $\begin{array}{l}\text { All ages } \\
2107 \text { random } \\
\text { sample }\end{array}$ & IgG-PT $\geq 30 \mathrm{FDA}-\mathrm{U} / \mathrm{ml}$ & $\begin{array}{l}33.32 \% \\
\text { Significant among age groups } \\
(p<0.0005)\end{array}$ \\
\hline & $\begin{array}{l}\text { September } 2014 \\
\text { to October } 2014\end{array}$ & & IgG-PT $\geq 80 \mathrm{IU} / \mathrm{ml}$ & $\begin{array}{l}169(9.90 \%) \\
\text { Aged } \geq 3 \text { years } 9.9 \%\end{array}$ \\
\hline
\end{tabular}


Table 2 continued

\begin{tabular}{|c|c|c|c|c|}
\hline$\overline{\text { Country }}$ & Design, period & $\begin{array}{l}\text { Age, } n \text {, sample } \\
\text { type }\end{array}$ & $\begin{array}{l}\text { Test and serological cut-off } \\
\text { value }\end{array}$ & Key findings \\
\hline [39] & $\begin{array}{l}\text { Prospective, } \\
\text { population- } \\
\text { based, active } \\
\text { surveillance } \\
2010 \text { to } 2012\end{array}$ & $\begin{array}{l}0-76 \text { years } \\
1825 \text { random } \\
\text { sample }\end{array}$ & PT $\operatorname{IgG}>30 \mathrm{IU} / \mathrm{ml}$ & $\begin{array}{l}49.15 \% \\
\text { Age years }(n): \\
0-1 \text { (192): } 57.29 \% \\
2-3 \text { (174): } 57.47 \% \\
4-6 \text { (178): } 28.65 \% \\
7-12 \text { (180): } 28.89 \% \\
13-15 \text { (190): } 44.74 \% \\
16-20 \text { (175): } 44.00 \% \\
21-30 \text { (193): 52.85\% } \\
31-40 \text { (182): } 57.14 \% \\
41-50 \text { (177): } 58.19 \% \\
51-76 \text { (184): } 61.41 \%\end{array}$ \\
\hline$[18]$ & $\begin{array}{l}\text { Prospective, } \\
\text { population- } \\
\text { based, case- } \\
\text { surveillance } \\
\text { January } 2010 \text { to } \\
\text { December } 2012\end{array}$ & $\begin{array}{l}\text { All ages } \\
1089 \text { suspected } \\
\text { cases }\end{array}$ & $\begin{array}{l}\text { Positive culture; positive PCR } \\
\text { test; 4-fold increase in } \\
\text { for paired sera; or a single } \\
\text { serum PT IgG } \\
>580 \mathrm{IU} / \mathrm{ml} \text { (if not } \\
\text { vaccinated during } 3 \text { years) }\end{array}$ & $\begin{array}{l}113 \text { confirmed cases; annual incidence } \\
23.52 / 100,000 \\
\text { Aged } 7 \text { - years, annual incidence: } \\
\text { symptoms-based } 64.76 / 100,000 \text {; } \\
\text { hospital screening } 2.69 / 100,000 \\
\text { Aged } 16-59 \text { years, annual incidence; } \\
\text { symptoms-based 10.58/100,000; } \\
\text { hospital screening } 0.24 / 100,000\end{array}$ \\
\hline$[78]$ & $\begin{array}{l}\text { Prospective, } \\
\text { population- } \\
\text { based } \\
\text { Circa } 2015\end{array}$ & $\begin{array}{l}0-74 \text { years } \\
2147 \text { random } \\
\text { sample }\end{array}$ & $\mathrm{PT}$ IgG $\geq 28 \mathrm{IU} / \mathrm{ml}$ & $\begin{array}{l}\text { Overall, } 66.28 \%: \\
\text { Aged }<1 \text { year: } 22.23 \% \\
\text { Aged }>10 \text { years: } 10.19-13.51 \%\end{array}$ \\
\hline$[75]$ & $\begin{array}{l}\text { Retrospective, } \\
\text { population- } \\
\text { based } \\
\text { October } 2012 \text { to } \\
\text { June } 2013\end{array}$ & $\begin{array}{l}\text { 3-18 years } \\
1032 \text { stored } \\
\text { serum from } \\
\text { routine child } \\
\text { clinic visits }\end{array}$ & $\begin{array}{l}\text { PT } \operatorname{IgG} \geq 0.1 \mathrm{IU} / \mathrm{ml} \text { (full } \\
\text { protection) }\end{array}$ & $\begin{array}{l}248(42.25 \%) \\
\text { Aged } 11 \text { years versus } 6 \text { years: } 93.68 \% \\
\text { versus } 69.84 \% ; p<0.001\end{array}$ \\
\hline
\end{tabular}


Table 2 continued

\begin{tabular}{|c|c|c|c|c|}
\hline Country & Design, period & $\begin{array}{l}\text { Age, } n \text {, sample } \\
\text { type }\end{array}$ & $\begin{array}{l}\text { Test and serological cut-off } \\
\text { value }\end{array}$ & Key findings \\
\hline$[33]$ & $\begin{array}{l}\text { Prospective, } \\
\text { clinic-based, } \\
\text { population- } \\
\text { based } \\
\text { October } 2013 \text { to } \\
\text { June } 2013\end{array}$ & $\begin{array}{l}\text { 3-18 years } \\
1032 \text { random } \\
\text { sample }\end{array}$ & $\begin{array}{l}\text { PT } \operatorname{IgG} \geq 40 \mathrm{IU} / \mathrm{ml} \\
\text { PT } \mathrm{IgG} \geq 100 \mathrm{IU} / \mathrm{ml}\end{array}$ & $\begin{array}{l}101(9787 / 100,000) \\
35(3390 / 100,000)\end{array}$ \\
\hline$[77]$ & $\begin{array}{l}\text { Prospective, } \\
\text { population- } \\
\text { based } \\
\text { September } 2010\end{array}$ & $\begin{array}{l}\text { 0-95 years } \\
1313 \text { random } \\
\text { sample }\end{array}$ & PT IgG $\geq 30 \mathrm{IU} / \mathrm{ml}$ & $\begin{array}{l}117(8.91 \%) \\
9395 / 100,000 \text { population }>7 \text { years } \\
11,561 / 100,000 \text { population } 41-50 \\
\text { years } \\
11,428 / 100,000 \text { population } 13-19 \\
\text { years }\end{array}$ \\
\hline [34] & $\begin{array}{l}\text { Cross-sectional } \\
\text { sero- } \\
\text { epidemiological } \\
\text { survey } \\
2011\end{array}$ & $\begin{array}{l}0-86 \text { years } \\
1080 \text { healthy } \\
\text { individulas }\end{array}$ & $\mathrm{PT} \operatorname{IgG}>30 \mathrm{U} / \mathrm{ml}$ & $\begin{array}{l}\text { Of the } 850 \text { subjects older than } 4 \text { years } \\
\text { of age, } 56(6.6 \%) \text { had anti-PT IgG } \\
\text { titers } \geq 30 \mathrm{IU} / \mathrm{ml} \text {, and } 11(1.3 \%) \text { had } \\
\text { titers } \\
\geq 80 \mathrm{IU} / \mathrm{ml} \\
\text { The highest proportion of anti-PT IgG } \\
\text { titers } \geq 30 \mathrm{IU} / \mathrm{ml} \text { occurred in the } \\
31-40 \text { years age group }\end{array}$ \\
\hline$[32]$ & $\begin{array}{l}\text { Prospective, } \\
\text { hospital-based, } \\
\text { case surveillance } \\
\text { November } 2008 \\
\text { to October } 2009\end{array}$ & $\begin{array}{l}\text { 2-20 years } \\
1616 \text { suspected } \\
\text { cases }\end{array}$ & $\begin{array}{l}\text { PT } \operatorname{IgG}>50 \mathrm{U} / \mathrm{ml} \\
(40 \mathrm{FDA}-\mathrm{U} / \mathrm{ml})\end{array}$ & $\begin{array}{l}\text { ( } 4.0 \%) 7000 / 100,000 \text { population aged } \\
3-20 \text { years } \\
\text { Peak incidences: } \\
\text { Aged 6-8 years; } 9100 / 100,000 \text { per year } \\
\text { Aged } 12-20 \text {-years; } 14,600 / 100,000 \text { per } \\
\text { year }\end{array}$ \\
\hline
\end{tabular}

PT IgG pertussis immunoglobulin G, GM geometric mean, FHA anti-filamentous hemagglutinin, LRTI lower respiratory tract infection, $C I$ confidence interval

in $\mathrm{Xi}^{\prime}$ an China in 2016 , the prevalence of pertussis was found to be $22 \%$ among 94 children aged 11-12 years [20].

In a study between 2008 and 2009 of 1616 serum samples from children and adolescents aged 2-20 years, the seroprevalence of anti-PT IgG $\geq 40$ Food and Drug Administration (FDA)$\mathrm{U} / \mathrm{ml}$ in those aged $\geq 3$ years was $4.0 \%(95 \%$ confidence intervals [CI] 3.0\%, 5.0\%), which was equivalent to an estimated incidence of B. pertussis infection of $7000 \quad(95 \% \quad$ CI $5300-8800) / 100,000$ per year in the year before serum sampling. There were two peaks of estimated incidence: 9100 (95\% CI 4300-14,000)/ 100,000 population per year the population aged $>6$ to 8 years, and $14,600 \quad(95 \%$ CI 
Table 3 Overview of studies of pertussis in children and adults in Taiwan and South Korea (by publication date)

\begin{tabular}{|c|c|c|c|c|}
\hline Country & Design, period & Age, $n$, sample type & $\begin{array}{l}\text { Test and } \\
\text { serological cut- } \\
\text { off value }\end{array}$ & Key findings \\
\hline $\begin{array}{c}\text { Taiwan } \\
{[21]}\end{array}$ & $\begin{array}{l}\text { Retrospective, } \\
\text { population-based, } \\
\text { surveillance } \\
2003 \text { to } 2017\end{array}$ & $\begin{array}{l}\text { All ages } \\
668 \text { confirmed cases }\end{array}$ & Culture and PCR & $\begin{array}{l}\text { Mean no. cases } 45 / \text { year } \\
\text { Mean incidence } 0.19 \text { cases } / 100,000 \\
\text { population } \\
\text { Aged } 1-4 \text { years, } 0.46 / 100,000 \text { population } \\
\text { Aged } 5-9 \text { years, } 0.14 / 100,000 \text { population } \\
\text { Aged } 15-39 \text { years, } 0.39 / 100,000 \\
\text { population } \\
\text { Aged } \geq 40 \text { years, } 0.03 / 100,000 \text { population }\end{array}$ \\
\hline $\begin{array}{c}\text { Taiwan } \\
{[41]}\end{array}$ & $\begin{array}{l}\text { Prospective, } \\
\text { population-based } \\
\text { September } 2012 \text { to } \\
\text { June } 2013\end{array}$ & $\begin{array}{l}\text { Elementary school } \\
936 \text { random sample } \\
\text { students }\end{array}$ & $\begin{array}{l}\text { PT } \\
\text { IgG }>11 \mathrm{NTU}\end{array}$ & $\begin{array}{l}98.89 \% \text { received } \geq 3 \text { doses } \mathrm{DTaP} \text { vaccine } \\
\text { Seropositive rate school grade } 1,49.36 \% \\
\text { Seropositive rate school grades } 1-4 \\
\text { significantly higher than grade } 5-6 \\
(37.18 \% \text { vs } 27.56 \%, p=0.002)\end{array}$ \\
\hline $\begin{array}{c}\text { Taiwan } \\
\text { [42] }\end{array}$ & $\begin{array}{l}\text { Prospective, } \\
\text { population-based } \\
2013\end{array}$ & $\begin{array}{l}\text { Elementary and } \\
\text { junior high school } \\
\text { children and } \\
\text { adolescents } \\
2782\end{array}$ & $\begin{array}{l}\text { PT } \\
\qquad \text { IgG }>11 \mathrm{NTU}\end{array}$ & $\begin{array}{l}42.5 \% \\
\text { Grade } 1-3,43.6-48.8 \% \text {; grade } 4-5 \text {, } \\
26.6-28.7 \% \text {; grade } 6-9,51.3 \%\end{array}$ \\
\hline $\begin{array}{c}\text { Taiwan } \\
\text { [22] }\end{array}$ & $\begin{array}{l}\text { Retrospective, } \\
\text { population-based, } \\
\text { case-surveillance } \\
1993 \text { to } 2004\end{array}$ & $\begin{array}{l}\text { All ages } \\
2452 \text { confirmed cases }\end{array}$ & Culture & $\begin{array}{l}\text { 2001-2004: incidence }<10 / 1 \text { million } \\
\text { population } \\
\text { 1993-2004: incidence decreased with } \\
\text { increasing age } \\
\text { Aged 1-9 years: incidence } 2-67 \text { cases/ } 1 \\
\text { million } \\
\text { Aged } 10-14 \text { years: incidence increased } \\
\text { from } 1 / 1 \text { million in } 1994 \text { to } 15 / 1 \text { million } \\
\text { in } 2004(p=0.03)\end{array}$ \\
\hline
\end{tabular}


Table 3 continued

\begin{tabular}{|c|c|c|c|c|}
\hline Country & Design, period & Age, $n$, sample type & $\begin{array}{l}\text { Test and } \\
\text { serological cut- } \\
\text { off value }\end{array}$ & Key findings \\
\hline \multirow{4}{*}{$\begin{array}{l}\text { South } \\
\text { Korea } \\
{[51]}\end{array}$} & $\begin{array}{l}\text { Prospective, hospital- } \\
\text { based }\end{array}$ & $\begin{array}{l}21-67 \text { years } \\
398 \mathrm{HCWs}\end{array}$ & $\begin{array}{l}\text { PT IgG 5-40 IU/ } \\
\text { ml }\end{array}$ & $121(30.4 \%)$ \\
\hline & 2011 & & $\begin{array}{l}\text { PT IgG Ab } \\
\quad 40-100 \mathrm{IU} / \mathrm{ml}\end{array}$ & $\begin{array}{l}10(2.5 \%) \\
\text { More frequently observed in } \\
\text { aged }>50 \text { years vs }<50 \text { years } \\
(p=0.017)\end{array}$ \\
\hline & & & $\begin{array}{l}\text { PT } \\
\text { IgG }>100 \mathrm{IU} / \\
\mathrm{ml}\end{array}$ & $\begin{array}{l}3(0.8 \%) \text { levels > } 100 \mathrm{IU} / \mathrm{mL}: \text { acute } \\
\text { infection }\end{array}$ \\
\hline & & & $\begin{array}{l}\text { anti-PT IgA } \\
\quad \text { level } \geq 125 \mathrm{IU} / \\
\quad \mathrm{ml}\end{array}$ & 0 \\
\hline $\begin{array}{l}\text { South } \\
\text { Korea } \\
{[52]}\end{array}$ & $\begin{array}{l}\text { Prospective, hospital- } \\
\text { based surveillance } \\
\text { July-December } 2012\end{array}$ & $\begin{array}{l}\text { Aged } \geq 11 \text { years } \\
1192 \text { residual sera }\end{array}$ & 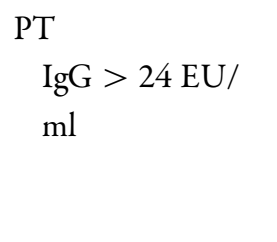 & $\begin{array}{l}41.4 \% \\
46.5 \% \geq 51 \text { years } \\
39.1 \%<51 \text { years } \\
\text { Older vs younger, } p=0.017\end{array}$ \\
\hline $\begin{array}{l}\text { South } \\
\text { Korea } \\
{[53]}\end{array}$ & $\begin{array}{l}\text { Prospective, hospital- } \\
\text { based, case- } \\
\text { surveillance } \\
\text { December } 2009 \text { and } \\
\text { December } 2011\end{array}$ & $\begin{array}{l}11-20 \text { years and } \\
\geq 21 \text { years } \\
310 \text { with persistent } \\
\text { cough of } 1-8 \text { weeks }\end{array}$ & $\begin{array}{l}\text { Culture and/or } \\
\text { PCR }\end{array}$ & $\begin{array}{l}73(24.5 \%) \\
20 / 86 \text { aged } 11-20 \text { years } \\
\text { Mean cough duration } 11.35 \pm 33.3 \text { days } \\
56 / 224 \text { aged } \geq 21 \text { years } \\
\text { Mean cough duration } 18.43 \pm 4.04 \text { days }\end{array}$ \\
\hline $\begin{array}{l}\text { South } \\
\text { Korea } \\
{[27]}\end{array}$ & $\begin{array}{l}\text { Retrospective, } \\
\text { population-based } \\
\text { passive and active } \\
\text { surveillance } \\
\text { 2001-2012 }\end{array}$ & $\begin{array}{l}\text { All ages } \\
\text { Population }\end{array}$ & $\begin{array}{l}\text { Clinically } \\
\text { suspected } \\
\text { pertussis }\end{array}$ & $\begin{array}{l}\text { 2001-2012: passive surveillance } 416 \text { cases, } \\
\text { highest age-specific incidence in infants } \\
\text { aged }<1 \text { year } \\
\text { In } 2011-2012 \text {, highest age-specific } \\
\text { incidence in groups aged }>20 \text { years and } \\
\text { aged } 15-20 \text { years }\end{array}$ \\
\hline $\begin{array}{l}\text { South } \\
\text { Korea } \\
{[28]}\end{array}$ & $\begin{array}{l}\text { Prospective, hospital- } \\
\text { based, case- } \\
\text { surveillance } \\
\text { July } 2011 \text { to June } \\
2012\end{array}$ & $\begin{array}{l}44.4 \pm 15.9 \text { years } \\
622 \text { with bothersome } \\
\text { cough }\end{array}$ & PCR & $\begin{array}{l}\text { Median cough duration was } 15.0 \text { days } \\
35(6.1 \%) \text { PCR-confirmed } \\
\text { Sputum, rhonchi, and post-tussive } \\
\text { vomiting more common in patients with } \\
\text { a positive PCR than those without } \\
(p=0.005, p=0.007 \text {, and } p=0.036 \text {, } \\
\text { respectively) }\end{array}$ \\
\hline
\end{tabular}


Table 3 continued

\begin{tabular}{|c|c|c|c|c|}
\hline Country & Design, period & Age, $n$, sample type & $\begin{array}{l}\text { Test and } \\
\text { serological cut- } \\
\text { off value }\end{array}$ & Key findings \\
\hline $\begin{array}{l}\text { South } \\
\text { Korea } \\
{[62]}\end{array}$ & $\begin{array}{l}\text { Prospective, case- } \\
\text { based, hospital } \\
\text { surveillance } \\
\text { September } 2009 \text { and } \\
\text { April } 2011\end{array}$ & $\begin{array}{l}45.9 \pm 15.2 \text { years } \\
934 \text { with bothersome } \\
\text { cough }\end{array}$ & $\begin{array}{l}\text { Isolation of } \\
\text { B. pertussis or } \\
\text { PCR }\end{array}$ & $\begin{array}{l}607 \text { cough lasting } \geq 2 \text { weeks } \\
504 \text { : fulfilled clinical criteria probable case } \\
5 \text { PCR-confirmed } \\
\text { Sputum, rhinorrhoea, and myalgia were less } \\
\text { common and dyspnoea was more } \\
\text { common in patients with a positive PCR } \\
\text { than those without }(p=0.037, \\
p=0.006, p=0.005 \text {, and } p=0.030, \\
\text { respectively) }\end{array}$ \\
\hline
\end{tabular}

PT IgG pertussis immunoglobulin G, GMT geometric mean titer, PCR polymerase chain reaction, ELISA enzyme-linked immunosorbent assay, $C I$ confidence interval, NTU NovaTech units

9100-20,100)/100,000 per year in the population aged 12-20 years [32]. Consistent with these results, among 1032 children and adolescents in China between 2012 and 2013, the seroprevalence of anti-PT IgG $\geq 40 \mathrm{IU} / \mathrm{ml}$ varied from $4.48 \%$ in children aged $7-11$ years to $11.76 \%$ in adolescents aged $12-18$ years [33].

\section{All Ages}

A seroprevalence study in China was conducted between 2009 and 2017 and included a population of 3360 [35]. Seropositivity (PT IgG $\geq 16 \mathrm{EU} / \mathrm{ml}$ ) was significantly lower in the age groups $<10$ years, 20-29 years, and 30-39 years compared with the other age groups evaluated [35]. Another study between 2010 and 2016, included 3058 randomly selected people aged 3-69 years (2010), and 826 people aged 20-39 years attending an annual medical examination (2015-2016). Comparing between the two periods, there was no difference in the seroprevalence of anti-PT IgG $\geq 40 \mathrm{IU} / \mathrm{ml}$ in the population aged $20-39$ years ( $5.1 \%$ versus $4.0 \%)$ [38].

The incidence rate calculated for China based upon 113 confirmed cases (see Table 2 for definition), from 1089 possible cases, identified through active symptom surveillance from 2010 to 2012, was highest in infants and young children (aged $<6$ years) [18]. The rate fell with age from $64.76 / 100,000$ in children aged 7-14 years to $10.58 / 100,000$ in adolescents and adults aged 15-69 years. The authors noted that the annual incidence was 23.52/100,000 persons, which was 16.22 times higher that obtained via hospital reports for the same period $(p<0.001)$. The actual incidence in the population aged 15-69 years was significantly underestimated by hospitals, given that it was 43.08 times that of the hospital rate. Among cases aged $<15$ years, $84.5 \%$ had been fully vaccinated. The misdiagnosis rate was as high as $94.69 \%$, and only $5.31 \%$ of the confirmed pertussis cases were properly diagnosed as pertussis at the first medical visit [18].

A Chinese study of people aged 0-95 years, conducted in 2010, reported that of 1313 people, 117 (8.91\%) were seropositive (PT IgG $>30 \mathrm{IU} / \mathrm{mL}$ ), and the estimated incidence of recent infection was 9395/100,000 for those aged $>7$ years [77]. The estimated incidence rate of recent infection peaked at 11,561/ 100,000 in those aged 41-50 years and at $11,428 / 100,000$ in those aged 13-19 years [77]. Another population-based Chinese study between 2010 and 2012, included 1825 randomly selected people aged 0-76 years, and found an overall seropositivity (PT IgG > $30 \mathrm{IU} /$ 
$\mathrm{mL}$ ) rate of $49.15 \%$. By age group, the seropositivity rate was substantially lower in children aged 4-12 years than in other groups $(p<0.001)$ [39].

In an analysis of 1080 samples taken from a range of people aged $0-86$ years in 2011, of 850 people aged $\geq 4$ years, $56(6.6 \%)$ had anti-PT IgG levels > $30 \mathrm{IU} / \mathrm{mL}$, and $11(1.3 \%)$ had anti PT-IgG levels of $>80 \mathrm{IU} / \mathrm{ml}$ [34]. The estimated age-specific incidence of infection (PT $\operatorname{IgG} \geq 30 \mathrm{IU} / \mathrm{mL}$ ) revealed a peak incidence in people aged $31-40$ years, followed by those aged 41-60 years. A higher prevalence of anti-PT IgG levels $>30 \mathrm{IU} / \mathrm{ml}$ was observed in adults aged $\geq 21$ years $(42 / 502 ; 8.4 \%)$ than the population aged $4-20$ years $(14 / 348,4.0 \%, p<0.05)$, ranging from $6.48 \%$ in children aged $<2$ years to $12.71 \%$ in adults aged $41-60$ years [34].

Of 2047 residents of Beijing in 2012, including people aged up to 74 years, the highest seropositivity (PT IgG $\geq 28 \mathrm{IU} / \mathrm{ml}$ ) rate was seen in infants aged $<1$ year at $22.23 \%$ [78]. In people aged $>10$ years, the seropositivity rate was $10.19-13.51 \%$ with no significant differences between the age groups. Those with anti-PT IgG $\geq 100 \mathrm{IU} / \mathrm{ml}$ were nearly all in the groups aged $>5$ years, although there were none in the group aged 10-14 years [78].

In an all age group survey of 1080 people in 2015 , the a rate of recent infection (PT IgG $>100 \mathrm{IU} / \mathrm{mL}$ ) was $1.17 \%$ (11/944), which was highest in adults aged $\geq 20$ years $(2.23 \%)$, but with no significant differences between age groups [36]. The estimated pertussis infection rate was 7290/100,000, which was far higher than the nationally reported incidence of 1.29 / 100,000 in 2015 . Peaks of estimated incidence of infection were found in children aged 7-14 years $(9971 / 100,000)$ and $\geq 20$ years $(13,898 /$ 100,000) [36].

Another large-scale survey in China in 2014 involving 2107 people aged up to 91 years showed that of 1707 people aged $\geq 3$ years, 169 $(9.90 \%)$ had evidence of a recent infection (PT IgG $>80 \mathrm{FDA}-\mathrm{U} / \mathrm{ml}$ ), with the highest proportion of recent infections among people aged $\geq 60$ years, followed by those aged 11-15 years and $16-25$ years [31].

\section{Burden}

There were two studies of clinical burden in China, of which one included 48 laboratoryconfirmed (mean age 42 years) cases in 2018 [59], and the other 26 laboratory-confirmed cases (aged 23-79 years) in 2009 [58]. Paroxysmal cough was a common symptom in both studies (47.8-54\%), followed by vomiting (19-30.4\%), yet whoop affected relatively few adults $(2-21 \%)$. In the latter study the most common symptoms were nocturnal cough $(69.2 \%)$ and persistent cough (68\%), and the authors noted that in adults, paroxysmal cough and whooping was less common than in infants, and although the severity of coughing was generally lower in adults than that reported in infants, the symptoms are similar in all ages [58].

\section{Taiwan}

Vaccination with wP started in Taiwan in 1954, and this was replaced by aP in the 1980s [21]. The NIP in Taiwan currently includes, DTP at 2, 4, 6, and 18 months, and tetanus, diphtheria, and pertussis (Tdap) at 5 years [79]. Tdap is recommended for pregnant women and caregivers, but is not state funded. Coverage of DTP4 in Taiwan is greater than 90\% [80]. Pertussis is a notifiable disease in Taiwan and confirmation tests are conducted at the Taiwan Center for Disease Control Laboratory [81].

In Taiwan, based on 668 cases reported to the Taiwanese Center for Disease Control and Prevention (CDC) from 2003 to 2017, the incidence rates of confirmed infection in infants accounted for the highest proportion of all cases $(49.8 \%)$. The mean incidence rates were 0.46 , $0.14,0.39,0.09$, and 0.03 cases $/ 100,000$ population, respectively, in children aged $>4$ years, 5-9 years, 10 -14 years, 15-39 years, and $>40$ years. Adolescents aged 10-14 years accounted for $12.4 \%$ [21]. A long-term survey of pertussis epidemiology in Taiwan between 1993 and 2004 among children aged $\leq 14$ years (2452 reported cases) found that the highest morbidity was in infants aged $<1$ year, and that there was a significant upward trend in the 
incidence of pertussis in infants aged $<1$ year and adolescents aged 10-14 years [22].

\section{South Korea}

DTP vaccination at $2,4,6$, and 15-18 months was introduced to NIP in South Korea in 1982, and Tdap for children aged 11-12 years was added in 2012 [51, 82]. Tdap for pregnant women and adults in contact with neonates has been recommended since 2017 [83]. A single dose of Tdap is also recommended for adults, with a booster dose every 10 years [84].

Based on WHO estimates, coverage of DTP3 was about 98\% in South Korea in 2019 [80]. Pertussis is a notifiable disease in Korea, and is monitored by the national sentinel surveillance system [85].

A large study in South Korea of 1192 healthy adolescents and adults in 2012 found that the pertussis seroprevalence (PT IgG $>24 \mathrm{EU} / \mathrm{ml}$ ) was $41.4 \%$ [52]. The seroprevalence was not significantly different between the age groups, although the seroprevalence in individuals aged $\geq 51$ years was significantly higher than in individuals aged $<51$ years $\quad(46.5 \%$ versus $39.1 \%, p=0.017)$ [52]. In South Korea in 2009-2011, among adolescents and adults ( $n=76$ laboratory-confirmed cases, unspecified cut-off value) divided into seven age groups (11-20 years, 21-30 years, 31-40 years, 41-50 years, 51-60 years, 61-70 years, and $\geq 71$ years), the group aged $11-20$ years $(26.3 \%)$ comprised the largest proportion of pertussis cases compared with the other six age groups; $6.6 \%, 15.8 \%, 13.2 \%, 15.8 \%, 17.1 \%$, and $5.3 \%$, respectively [53].

In a study in Korea of 398 HCWs aged 21-67 years, including doctors, nurses, healthcare assistants, and non-clinical workers, overall, $121(30.4 \%)$ had anti-PT IgG 5-40 IU/ml, and 3 had anti-PT IgG $>100 \mathrm{IU} / \mathrm{ml}$, yet none had anti-PT IgG $\geq 125 \mathrm{IU} / \mathrm{ml}$. By age group, those aged $>50$ years had the highest mean antibody titer [51].

\section{Burden}

In a small outbreak study of nine cases identified at an elementary school (five aged $<8$ years and four aged 9-10 years) in South Korea in 2017 , one case $(11 \%)$ required hospitalization [64]. All cases had cough, one (11\%) had posttussive vomiting, and one (11\%) had fever. The overall pertussis attack rate in the school was $1 \%$. Pertussis PCR-confirmed in eight cases and eight cases received antibiotics [64].

In a case-based surveillance study in South Korea between 2009 and 2011, among 504 probable cases defined by clinical criteria, paroxysmal cough (90.8\%) and sputum (60.4\%) were the most common symptoms. There were five PCR-confirmed cases, which had a median cough duration of 30 days (interquartile range [IQR] 18.0-50.0 days). Sputum, rhinorrhoea, and myalgia were less frequent, and dyspnoea was more frequent in the clinical cases compared with PCR-confirmed cases $(p=0.037$, $p=0.006, p=0.005$, and $p=0.030$, respectively) [62]. An abstract of a similar study in South Korea conducted between 2011 and 2012 included 578 adults (age, $44.4 \pm 15.9$ years) with a median cough duration of 15.0 days (IQR, 7.0-30.0 days). Thirty-five (6.1\%) cases were PCR-confirmed, and sputum, rhonchi, and post-tussive vomiting were more common in patients with a positive PCR than those without $(p=0.005, p=0.007$, and $p=0.036$, respectively) [28].

\section{SOUTH AND SOUTHEAST ASIA}

There were only four publications identified in South and Southeast Asian countries (Table 4).

\section{Singapore}

The NIP in Singapore includes DTP at 2, 4, 6, and 18 months, and a Tdap booster for children aged 10-11 years [86]. Tdap vaccination for pregnant women and adults in close contact with neonates has been recommended in Singapore since 2017 [87]. Tdap is also recommended for adults aged 19-64 years every 10 years, and for healthcare personnel who have direct patient contact [88]. Coverage of DTP3 in Singapore was greater than $98 \%$ in 2019 [80]. 
Table 4 Overview of studies of pertussis in children and adults in South and Southeast Asia

\begin{tabular}{|c|c|c|c|}
\hline Country & Design, period & Age, $n$, sample type & Key findings \\
\hline India [29] & $\begin{array}{l}\text { Retrospective, population-based } \\
\text { (outbreak in remote region) } \\
\text { 6-15 August } 2007\end{array}$ & $\begin{array}{l}<6 \text { years } \\
72 \text { suspected cases } \\
\text { from population } \\
2471\end{array}$ & $\begin{array}{l}\text { Attack rate } 13 \% \text { (age } 3-60 \text { months) } \\
30 \text { reported deaths } \\
26 \text { deaths aged }<5 \text { years; } 15 \text { infants }\end{array}$ \\
\hline $\begin{array}{l}\text { Thailand } \\
\text { [54] }\end{array}$ & $\begin{array}{l}\text { Prospective, population-based } \\
\text { October } 2010 \text { to February } 2011\end{array}$ & $\begin{array}{l}15-85 \text { years } \\
76 \text { patients with } \\
\text { cough }>2 \text { weeks }\end{array}$ & $\begin{array}{l}\text { Evidence of acute infection: } 14 \text { (18.4\%), mean age } \\
59 \text { years, mean duration cough } 34 \text { days, had } \\
\text { PCR-diagnosed: } 13 \text { cases }\end{array}$ \\
\hline $\begin{array}{l}\text { Singapore } \\
{[44]}\end{array}$ & $\begin{array}{l}\text { Prospective, population-based } \\
2 \text { days in August } 2002\end{array}$ & $\begin{array}{l}\text { 18-45 years } \\
270 \text { random sample } \\
\text { 92: } 18-25 \text { years } \\
\text { 89: } 26-35 \text { years } \\
\text { 89: } 36-45 \text { years }\end{array}$ & $\begin{array}{l}261(97 \%) \text { positive serology: } \\
96 \% \text { in the } 18 \text { to } 25 \text { years cohort, } \\
99 \% \text { in the } 26 \text { to } 35 \text { years old cohort } \\
96 \% \text { in the } 36 \text { to } 45 \text { years old cohort }\end{array}$ \\
\hline $\begin{array}{l}\text { Singapore } \\
{[43]}\end{array}$ & $\begin{array}{l}\text { Prospective, hospital-based case } \\
\text { surveillance } \\
\text { August } 2008 \text { to July } 2010\end{array}$ & $\begin{array}{l}1-17 \text { years } \\
1200\end{array}$ & Seroprevalence $60.8 \%$ (95\% CI 58.0-63.5\%) \\
\hline
\end{tabular}

CI confidence interval

In Singapore, 270 people with a median age of 30 years were enrolled in a study in 2002 . Positive anti-PT IgG levels (unspecified cut-off value) were found in $97 \%$ of the population, and seropositivity was not associated with age, gender, or race. The authors noted that the seroprevalence in adults was much higher than the previously documented seroprevalence of around $50 \%$ in the adolescent age group in Singapore, and that this was most likely due to natural infection [44]. In a hospital-based study in Singapore, between 2008 and 2010, among 1200 children aged $1-7$ years, the prevalence of anti-PT IgG $>22 \mathrm{IU} / \mathrm{ml}$ was $60.8 \%(95 \% \mathrm{CI}$ $58.0-63.5 \%)$. This ranged from $64 \%$ in children aged $1-6$ years to $55 \%$ in those aged $13-17$ years [43].

\section{India}

DTP was added to the NIP in India in 1978 , and the current schedule includes DTP at 6, 10, and 14 weeks, and at 15-18 months and at 5 years
[89]. According to WHO, DTP3 coverage in India in 2019 was 89\% [80].

There was one study in India and this reported pertussis cases during an outbreak in 2007 in the Sarli circle region, comprising 2471 people in 26 villages [29]. The overall attack rate, based on clinical suspicion, was $30 \%$ and none of the cases had been vaccinated. Among children aged $<6$ years with suspected pertussis (all had cough of at least 2 weeks duration), common clinical features of the 72 case-patients identified in the medical camp were paroxysms of coughing (100\%) and post-tussive vomiting $(100 \%)$, yet inspiratory whooping was uncommon $(1.3 \%)$.

\section{Thailand}

In Thailand, the NIP includes DTP at 2, 4, 6, months, and at $12-18$ months and at 4 years [90]. According to WHO, DTP3 coverage in Thailand in 2019 was 97\% [80]. 
Table 5 Overview of studies of pertussis in children and adults in multinational studies

\begin{tabular}{|c|c|c|c|c|}
\hline Country & Design, period & $\begin{array}{l}\text { Age, } n, \\
\text { sample type }\end{array}$ & $\begin{array}{l}\text { Test and } \\
\text { serological cut- } \\
\text { off value }\end{array}$ & Key findings \\
\hline $\begin{array}{l}\text { India, Thailand, Korea, } \\
\text { China, Sri Lanka, } \\
\text { and Japan [56] }\end{array}$ & $\begin{array}{l}\text { Prospective, } \\
\text { population- } \\
\text { based } \\
\text { July } 2013 \text { to June } \\
2016\end{array}$ & $\begin{array}{l}\text { 10-18 years } \\
1894 \\
\text { convenience } \\
\text { population } \\
\text { sample }\end{array}$ & $\begin{array}{l}\mathrm{PT} \\
\mathrm{IgG} \geq 62.5 \mathrm{IU} / \\
\mathrm{ml}\end{array}$ & $\begin{array}{l}87(4.8 \%) \\
73(83.9 \%) \text { had received } \geq 3 \text { doses } \\
\text { pertussis vaccine age }<6 \text { years } \\
30 \text { had persistent cough during the } \\
\text { past } 6 \text { months } \\
\text { No significant difference in } \\
\text { proportions with recent infection } \\
\text { among age groups }\end{array}$ \\
\hline $\begin{array}{l}\text { Malaysia, Taiwan, and } \\
\text { Thailand [55] }\end{array}$ & $\begin{array}{l}\text { Prospective, } \\
\text { outpatient- } \\
\text { based, } \\
\text { population- } \\
\text { based } \\
\text { June } 2012 \text { and } \\
\text { May } 2013\end{array}$ & $\begin{array}{l}\geq 19 \text { years } \\
312 \text { cough for } \\
5-14 \text { days }\end{array}$ & $\begin{array}{l}\text { PT } \\
\qquad \underset{\mathrm{IgG}}{\mathrm{ml}} \geq 100 \mathrm{IU} /\end{array}$ & $\begin{array}{l}16(5.13 \%) \\
50-59 \text { years }(9.8 \%, 5 / 51,95 \% \text { CI } \\
3.26-21.41) \text { and } 19-29 \text { years }(7.6 \% \text {, } \\
5 / 66,95 \% \text { CI } 2.51-16.80) \\
\text { Most common in } 19-29 \text { years age } \\
\text { group }(3.0 \%, 2 / 66)\end{array}$ \\
\hline
\end{tabular}

PT IgG pertussis immunoglobulin $\mathrm{G}$

In a small study in Thailand between 2010 and 2011, among 76 patients with persistent cough of duration of at least 2 weeks, 14 (18.4\%) had evidence of acute infection of pertussis (unspecified cut-off value) [54]. The mean age of pertussis cases was 59 years (range 28-85 years) and the mean duration of cough was 34 days (range 14-120 days).

\section{Pan-Asia}

Two publications were identified which provided data from several countries (Table 5). The most recent multinational study assessed the seroprevalence of anti-PT $\mathrm{IgG} \geq 62.5 \mathrm{IU} / \mathrm{ml}$ in six Asian countries between 2013 and 2016, including 1802 children/adolescents aged 10-18 years [56]. The children had received five (India, Thailand, Taiwan, and Korea) or four (China, Sri Lanka, and Japan) doses of DTP before the age of 6 years. The rates of anti-PT $\mathrm{IgG} \geq 62.5 \mathrm{IU} / \mathrm{ml}$ by age group were not significant: aged $10-12$ years, $4.6 \%$; aged $13-15$ years,
$5.6 \%$, and $16-18$ years, $4.1 \%$. The main finding was that 1 in 20 had serologic evidence of recent infection regardless of vaccination background [56].

The other multinational study assessed the seroprevalence of pertussis in Malaysia, Taiwan and Thailand between 2012 and 2013, including adults aged $\geq 19$ years [55]. A total of 312 adults were recruited from outpatient settings after consulting for chronic coughing for 5-14 days, of which $5.13 \%$ had serological evidence of pertussis infection (PT IgG $\geq 62.5 \mathrm{IU} /$ $\mathrm{ml}$ ) within the previous 12 months, and $1.3 \%$ had evidence of active or recent infection (PT $\mathrm{IgG} \geq 100 \mathrm{IU} / \mathrm{ml}$ ). The most common symptom was paroxysmal coughing (75\%) followed by nocturnal coughing $(68.8 \%)$ and chest pain $(62 \%)$, and a longer duration of cough, paroxysms, and breathlessness/chest pain were associated with being seropositive (PT IgG $\geq 10 \mathrm{IU} /$ $\mathrm{ml})$ versus seronegative [55]. 


\section{DISCUSSION}

Most of the studies identified for this review of pertussis in Asia were from Japan, China, South Korea, Taiwan, and Singapore. Despite high DTP4 or DTP5 coverage in these countries, pertussis is circulating, and the peak age of infection appears to be shifting away from infants and young children, and towards adolescents. However, information is unavailable in many LMICs in Asia, meaning that it is difficult to assess the circulation of pertussis and the effect of vaccination across the continent.

In the USA, Canada, Australia, and several European countries, high DTP4 coverage led to a dramatic decrease in the incidence of pertussis in infants and young children, yet despite high vaccine coverage, a resurgence of pertussis has been observed in many countries $[91,92]$. Over the past decade there have been global epidemic outbreaks of pertussis every 3-5 years, and in 2012, there were epidemic outbreaks in Canada, Australia, France, the UK, Japan, and the USA [93-97]. In the USA in 2012, there were 48,277 notified cases of pertussis, up from 9771 a decade before, and the highest level since 1955 [98]. During epidemic outbreaks, the highest burden of severe cases is typically among unvaccinated or partly vaccinated infants [93-97]. For example, in 2012 in the UK, 14 infants aged $<3$ months died, and in the USA, 14 infants aged $<12$ months died [99, 100]. During an epidemic outbreak in California in 2010, there were about 9000 cases, 808 hospitalizations, and 10 infant deaths [101, 102]. Several high-income countries have introduced aP vaccination for pregnant women, including the USA in 2011, the UK in 2012, and Australia in 2012 [103-105]. Whereas more studies are needed to assess the effectiveness of maternal pertussis vaccination programs, studies from the UK, Australia, and the USA show that aP vaccine during or after pregnancy reduced the risk of pertussis in neonates $[100,101,106]$. The Global Pertussis Initiative (GPI) recommends vaccination during pregnancy as a primary prevention strategy, or vaccinating all individuals who have close contact with infants younger than 6 months [105, 107]. In Asia,
Singapore, South Korea, and Hong Kong, aP vaccination for pregnant women is included in the NIP $[83,87,108]$, and whereas it is recommended in Japan and Taiwan, it is not state funded [72, 79].

Globally, high DTP4 coverage has led to a change in the epidemiology of pertussis infection, characterised by a shift in the peak age of infection away from infants, and towards young children, and the introduction of a booster dose at school entry further increased the peak age of infection towards adolescents and adults $[7,8]$. For example, after the introduction of a booster dose for children aged 5 years in Denmark in 2004, whereas cases decreased dramatically in the target population, the proportion of cases in adults aged $\geq 20$ years increased from $14 \%$ to $43 \%$ [109]. Similarly, in the Netherlands, a preschool booster was introduced in 2005, which decreased infection rates in young children, yet pertussis notifications increased by $60 \%$ in adolescents aged $10-19$ years, by $44 \%$ in adults aged $20-59$ years, and by $68 \%$ in adults aged $>60$ years [110]. On the basis of the these and other data, about 15 years ago, the GPI, the Consensus on Pertussis Booster Vaccine in Europe, and the US Advisory Committee on Immunization Practices (ACIP) recommended that adolescents and adults receive pertussis booster vaccination, and that Tdap vaccine should be given every 10 years to adults to improve community protection [7, 111, 112].

In the USA, the introduction Tdap vaccine for adolescents in 2005 resulted in a large decrease in pertussis cases among adolescents aged 11-18 years, and in Australia, after vaccinating high school children in 2008-2009, there was a decrease in pertussis cases in adolescents [113, 114]. Numerous countries, such as Australia, Canada, and France, include Tdap vaccine for adolescents in the NIP, yet the only countries to include 10-year booster doses for adults are Canada, Belgium, Germany, Italy, and Greece, and countries that include boosters specifically for elderly adults are Australia and the Czech Republic $[115,116]$.

In East Asian countries, including Japan and China, the NIPs currently include DTP4, and in South Korea, Hong Kong, and Taiwan the NIPs currently include DTP4, plus a DTP5 booster at 
age 6 years in Hong Kong, age 7 years in South Korea, and age 5-7 years in Taiwan [31]. In Japan, there is a voluntary recommendation for booster doses at age $>7.5$ years and 11-12 years, yet this is not state funded [72]. Among ASEAN countries, Cambodia, Laos, Myanmar, and the Philippines provide DTP3, Indonesia, Malaysia, and Vietnam provide DTP4, and Brunei, Singapore, and Thailand provide DTP5 [17]. The NIP in India includes DTP5, and although the Indian Paediatric Society recommends Tdap vaccine for children aged 12-14 years, this is not state funded [89]. Tdap vaccine for adolescents is included in the NIPs of South Korea, Singapore, and Hong Kong $[117,118]$.

Similar to Europe and the USA, numerous population-based, active and passive surveillance studies from East Asian countries show that high DTP4 coverage has decreased the incidence of pertussis in infants, and has changed the incidence and immunity profiles of pertussis across the general population. In Japan, there have been several outbreaks of pertussis over the past two decades including schools, universities, hospitals, and workplaces, showing that pertussis infection persists with cyclical epidemics [16, 48, 60, 61, 119]. Similarly, the most recent study from the Taiwan CDC open database showed that between 2003-2008 and 2009-2015, there was a twofold increase in pertussis cases (unspecified serological cut-off value) in adolescents, with peaks of incidence in 2009, 2011, and 2014 [22]. School outbreaks in China show that pertussis is circulating in young children, advocating a booster dose for children of school entry age [19]. Moreover, studies in China suggest that pertussis may be underestimated, particularly in adolescents and adults who are reported to be the new high-risk populations [31, 34, 77].

A recent systematic literature review of pertussis in ASEAN countries reported that immunization schedules and vaccination coverage rates vary across the region and disease surveillance is suboptimal meaning that the true burden is unknown [17]. However, a study of adolescents in India, Thailand, Taiwan, Korea, China, Sri Lanka, and Japan showed that between 2013 and 2016, 1 in 20 individuals had serological evidence of recent infection (PT IgG $\geq 62.5 \mathrm{IU} / \mathrm{ml}$ ), regardless of vaccination background [56]. Moreover, the countries have various economic status and infectious disease burdens, yet the anti-PT IgG levels among adolescents from different countries were similar. The seroprevalence of recent infection was estimated at $2.2-6.1 \%$, and although this demonstrates that pertussis persists in adolescents in Asia, the authors noted that serological data were not available for most countries [56].

In high-income countries, with high vaccine coverage among infants and young children, the GPI recommends Tdap vaccine for adolescents, with a booster every 10 years, as well as aP vaccine for pregnant women [7]. The only countries in Asia to follow these recommendations are South Korea, Hong Kong, and Singapore, yet there are no available data evaluating the effect of vaccination on the target populations or general populations. In LMICs, the GPI recommends aiming for high DTP4 coverage, and states that pregnant women should receive aP vaccine as a priority [120]. However, the scarcity of data from numerous Asian countries means that the effect of vaccination, particularly in remote rural areas, is difficult to assess. Although the real extent of pertussis-related morbidity and mortality is not known in many countries, the burden of pertussis in LMICs should not be underestimated [120, 121].

The main limitation of this review is that it provides a narrative analysis; however, the variations in methods used to assess pertussis across the articles identified meant that a statistical comparison was not feasible. Furthermore, there was a lack of data from several countries, particularly in Southeast Asia, and for countries with robust national surveillance, there was a wide variation in reporting systems, with differing methods used for passive and active surveillance, clinical definitions, laboratory diagnostics, and antibody cut-off levels. A strength of the review was the systematic searches used to identify information about pertussis in older children and adults in Asia, whereas previous reviews have focussed on infants and young children. 


\section{CONCLUSIONS}

In East Asia, including high-income countries such as Japan and South Korea, and higher middle-income nations including China and Taiwan, DTP4 coverage is high, yet passive and active surveillance show that pertussis is circulating in older children and adults [18-26, 28, 30-42, 45-53]. There are limited data from LMICs in Asia because surveillance is weak or absent, meaning that the true burden of pertussis among older populations is unknown.

\section{ACKNOWLEDGEMENTS}

Funding. Sponsorship for this study and the journal's Rapid Service Fee were funded by Sanofi Pasteur, France.

Editorial Assistance. The authors acknowledge Annick Moon of inScience Communications, Springer Healthcare Ltd, Chester, UK for editorial assistance with the preparation of this manuscript. This assistance was funded by Sanofi Pasteur. The authors also thank Burnedette Rose-Hill for editorial assistance and manuscript coordination on behalf of Sanofi Pasteur.

Authorship. All named authors meet the International Committee of Medical Journal Editors (ICMJE) criteria for authorship for this article, take responsibility for the integrity of the work as a whole, and have given their approval for this version to be published.

Authors' Contributions. Denis Macina Conceptualization, methodology, investigation, Writing - review and editing. Keith Evans - Methodology, investigation, Writing -review and editing.

Disclosures. Denis Macina is an employee of Sanofi Pasteur. Keith Evans was provided with funding by Sanofi Pasteur to conduct the literature review in collaboration with Denis Macina.
Compliance with Ethics Guidelines. This article is based on previously conducted studies and does not contain any studies with human participants or animals performed by any of the authors.

Data Availability. Data sharing is not applicable to this article as no datasets were generated or analysed during the current study.

Open Access. This article is licensed under a Creative Commons Attribution-NonCommercial 4.0 International License, which permits any non-commercial use, sharing, adaptation, distribution and reproduction in any medium or format, as long as you give appropriate credit to the original author(s) and the source, provide a link to the Creative Commons licence, and indicate if changes were made. The images or other third party material in this article are included in the article's Creative Commons licence, unless indicated otherwise in a credit line to the material. If material is not included in the article's Creative Commons licence and your intended use is not permitted by statutory regulation or exceeds the permitted use, you will need to obtain permission directly from the copyright holder. To view a copy of this licence, visit http://creativecommons.org/licenses/bync/4.0/.

\section{REFERENCES}

1. World Health Organization. Pertussis vaccines: WHO position paper, August 2015-recommendations. Vaccine. 2016;34(12):1423-5.

2. World Health Organization. Global and regional immunization profile: global. 2020. https://www. who.int/immunization/monitoring_surveillance/ data/gs_gloprofile.pdf. Accessed Nov 2020.

3. Domenech de Cellès M, Magpantay FM, King AA, Rohani P. The pertussis enigma: reconciling epidemiology, immunology and evolution. Proc Biol Sci. 1822;2016(283):20152309.

4. Cagney M, MacIntyre CR, McIntyre P, Torvaldsen S, Melot V. Cough symptoms in children aged 5-14 years in Sydney, Australia: non-specific cough or unrecognized pertussis? Respirology. 2005;10(3): 359-64. 
5. World Health Organization. SAGE pertussis working group. 2014. https:/www.who.int/immunization/ sage/meetings/2014/april/1_Pertussis_background_ FINAL4_web.pdf. Accessed Sept 2020.

6. World Health Organization. WHO Strategic Advisory Group of Experts Pertussis Working Group background paper. 2014. http://www.who.int/ immunization/sage/meetings/2014/april/1_Pertuss is_background_FINAL4_web.Pdf. Accessed Sept 2020 .

7. Esposito S, Principi N. Immunization against pertussis in adolescents and adults. Clin Microbiol Infect. 2016;22(Suppl 5):S89-s95.

8. Celentano LP, Massari M, Paramatti D, Salmaso S, Tozzi AE. Resurgence of pertussis in Europe. Pediatr Infect Dis J. 2005;24(9):761-5.

9. Barkoff AM, Mertsola J, Guillot S, Guiso N, Berbers G, He Q. Appearance of Bordetella pertussis strains not expressing the vaccine antigen pertactin in Finland. Clin Vaccine Immunol. 2012;19(10):1703-4.

10. Queenan AM, Cassiday PK, Evangelista A. Pertactinnegative variants of Bordetella pertussis in the United States. N Engl J Med. 2013;368(6):583-4.

11. Pawloski LC, Queenan AM, Cassiday PK, et al. Prevalence and molecular characterization of pertactin-deficient Bordetella pertussis in the United States. Clin Vaccine Immunol. 2014;21(2):119-25.

12. Lam C, Octavia S, Ricafort L, et al. Rapid increase in pertactin-deficient Bordetella pertussis isolates, Australia. Emerg Infect Dis. 2014;20(4):626-33.

13. Hackett C. Which 7 countries hold half the world's population? 2018. https://www.pewresearch.org/ fact-tank/2018/07/11/world-population-day/. Accessed Sept 2020.

14. Yeung KHT, Duclos P, Nelson EAS, Hutubessy RCW. An update of the global burden of pertussis in children younger than 5 years: a modelling study. Lancet Infect Dis. 2017;17(9):974-80.

15. World Health Organization. Global and regional immunization profile. South East Asia Region. 2020. https://www.who.int/immunization/monitoring surveillance/data/gs_searprofile.pdf?ua $=1$. Accessed Sept 2020.

16. World Health Organization. Global and regional immunization profile. Western Pacific Region. 2020. https://www.who.int/immunization/ monitoring_surveillance/data/gs_wprprofile. pdf?ua=1. Accessed Sept 2020.

17. Thisyakorn U, Tantawichien T, Thisyakorn C, Buchy P. Pertussis in the Association of Southeast
Asian Nations: epidemiology and challenges. Int J Infect Dis. 2019;87:75-83.

18. Huang H, Zhu T, Gao C, et al. Epidemiological features of pertussis resurgence based on community populations with high vaccination coverage in China. Epidemiol Infect. 2015;143(9):1950-6.

19. Huang H, Gao P, Gao Z, et al. A big pertussis outbreak in a primary school with high vaccination coverage in northern China: an evidence of the emerging of the disease in China. Vaccine. 2018;36(52):7950-5.

20. Liu X, Wang Z, Zhang J, et al. Pertussis outbreak in a primary school in China: infection and transmission of the macrolide-resistant Bordetella pertussis. Pediatr Infect Dis J. 2018;37(6):e145-8.

21. Chang IF, Lee P-I, Lu C-Y, Chen J-M, Huang L-M, Chang L-Y. Resurgence of pertussis in Taiwan during 2009-2015 and its impact on infants. J Microbiol Immunol Infect. 2019;52(4):542-8.

22. Lin Y-C, Yao S-M, Yan J-J, et al. Epidemiological shift in the prevalence of pertussis in Taiwan: implications for pertussis vaccination. J Med Microbiol. 2007;56(Pt 4):533-7.

23. Griffith MM, Fukusumi M, Kobayashi Y, et al. Epidemiology of vaccine-preventable diseases in Japan: considerations for pre-travel advice for the 2019 Rugby World Cup and 2020 Summer Olympic and Paralympic Games. Western Pac Surveill Response J. 2018;9(2):26-33.

24. Nakamura K, Kobayashi M, Yamamoto N, et al. Pertussis outbreak among patients and healthcare workers in a provincial dialysis facility in Japan. J Hosp Infect. 2016;94(4):341-5.

25. Sonoda S, Gotoh Y, Bann F, Nakayama T. Acute lower respiratory infections in hospitalized children over a 6 year period in Tokyo. Pediatrics Int. 1999;41(5):519-24.

26. Tanaka Y, Fujinaga K, Goto A, et al. Outbreak of pertussis in a residential facility for handicapped people. Dev Biol Stand. 1991;73:329-32.

27. Choe Y, Jun Woo K, Park Y-J, Jung C, Bae G-R. Burden of pertussis is underestimated in South Korea: a result from an active sentinel surveillance system. Jpn J Infect Dis. 2014;67:203-32.

28. Park SH, Lee MG, Lee KH, et al. A multicenter study of pertussis infection in patients with coughing in Korea, PCR-based study. Respirology. 2012;17:109.

29. Takum T, Gara D, Tagyung H, Murhekar MV. An outbreak of pertussis in Sarli Circle of Kurung- 
kumey district, Arunachal Pradesh, India. Indian Pediatr. 2009;46(11):1017-20.

30. Chen C-C, Balderston McGuiness C, Krishnarajah $\mathrm{G}$, et al. Estimated incidence of pertussis in people aged $<50$ years in the United States. Hum Vaccin Immunother. 2016;12(10):2536-45.

31. He H, Yao P, Zhou Y, Deng X, Pan J. Is pertussis infection neglected in China? Evidence from a seroepidemiology survey in Zhejiang, an Eastern Province of China. PLoS ONE. 2016;11(5): e0155965.

32. Wang C-Q, Zhu Q-R. Seroprevalence of Bordetella pertussis antibody in children and adolescents in China. Pediatr Infect Dis J. 2011;30(7):593-6.

33. Wu Y, Zhu B, Gao Y, et al. Clustered cases of Bordetella pertussis infection cause high levels of IgG antibodies against pertussis toxin in adolescents in Gaobeidian city, China. Epidemiol Infect. 2013;142(4):738-43.

34. Xu Y, Wang L, Xu J, et al. Seroprevalence of pertussis in China: need to improve vaccination strategies. Hum Vaccin Immunother. 2014;10(1): 192-8.

35. Xu Y, Xu E, Liu S, et al. Seroepidemiology of pertussis in Hangzhou, China, during 2009-2017. Hum Vaccines Immunother. 2019;15(11):2564-70.

36. Yao N, Zeng Q, Wang Q. Seroepidemiology of diphtheria and pertussis in Chongqing, China: serology-based evidence of Bordetella pertussis infection. Public Health. 2018;156:60-6.

37. Zhang Q, Han F, Nie Q, et al. Seroprevalence of antibodies to pertussis and diphtheria among healthy adults in China. J Infect. 2011;63(6):441-6.

38. Zhang Y, Chen Z, Zhao J, et al. Increased susceptibility to pertussis in adults at childbearing age as determined by comparative seroprevalence study, China 2010-2016. J Infect. 2019;79(1):1-6.

39. Zhang Y, Huang H, Gao Z, et al. A sera-epidemiological study on pertussis immunity levels among community populations and an analysis of the underlying factors in Tianjin China. Vaccine. 2015;33(51):7183-7.

40. Chiu TF, Lee CY, Lee PI, Lu CY, Lin HC, Huang LM. Pertussis seroepidemiology in Taipei. J Formos Med Assoc. 2000;99(3):224-8.

41. Kuo C-C, Huang Y-C, Hsieh Y-C, Huang Y-L, Huang Y-C, Hung Y-T. Seroepidemiology of pertussis among elementary school children in northern Taiwan. J Microbio Immunol. 2017;50(3):327-32.
42. Lu C-Y, Tsai H-C, Huang Y-C, Huang DT-N, Liu C-C, Huang L-M. A national seroepidemiologic survey of pertussis among school children in Taiwan. Pediatr Infect Dis J. 2017;36(12):e307-12.

43. Lai FY, Thoon KC, Ang LW, et al. Comparative seroepidemiology of pertussis, diphtheria and poliovirus antibodies in Singapore: waning pertussis immunity in a highly immunized population and the need for adolescent booster doses. Vaccine. 2012;30(24):3566-71.

44. Wilder-Smith A, Ng S, Earnest A. Seroepidemiology of pertussis in the adult population of Singapore. Ann Acad Med Singapore. 2006;35(11):780-2.

45. Fumimoto R, Otsuka N, Kamiya H, et al. Seroprevalence of $\operatorname{IgA}$ and IgM antibodies to Bordetella pertussis in healthy Japanese donors: assessment for the serological diagnosis of pertussis. PLoS ONE. 2019;14(7):e0219255.

46. Higa F, Haranaga S, Tateyama M, et al. Assessment of serum anti-Bordetella pertussis antibody titers among medical staff members. Jpn J Infect Dis. 2008;61(5):371-4.

47. Ikematsu H, Kawai N, Yajima S. A cross sectional survey measuring sero-incidence of pertussis infection among Japanese junior and senior high school students in 2013 and 2014. Vaccine. 2017;35(31): 3859-64.

48. Miyashita N, Kawai Y, Yamaguchi T, Ouchi K, Kurose K, Oka M. Outbreak of pertussis in a university laboratory. Intern Med. 2011;50(8):879-85.

49. Okada K, Ueda K, Morokuma K, Kino Y, Tokugawa K, Nishima S. Seroepidemiologic study on pertussis, diphtheria, and tetanus in the Fukuoka area of southern Japan: seroprevalence among persons 0-80 years old and vaccination program. Jpn J Infect Dis. 2004;57(2):67-71.

50. Anis E, Moerman L, Ginsberg G, et al. Did two booster doses for schoolchildren change the epidemiology of pertussis in Israel? J Public Health Policy. 2018;39(3):304-17.

51. Choi WS, Kim SH, Park DW. Seroprevalence of pertussis in healthcare workers without adult pertussis vaccine use at a university hospital in Korea. J Korean Med Sci. 2018;33(50):e321.

52. Lee SY, Han SB, Bae EY, et al. Pertussis seroprevalence in Korean adolescents and adults using antipertussis toxin immunoglobulin G. J Korean Med Sci. 2014;29(5):652-6.

53. Lee SY, Han SB, Kang JH, Kim JS. Pertussis prevalence in Korean adolescents and adults with persistent cough. J Korean Med Sci. 2015;30(7):988-90. 
54. Siriyakorn N, Leethong P, Sripakdee S, Kerdsin A, Dejsirilert S, Tantawichien T. Aetiologies of prolonged cough in Thai adults: the roles of Bordetella pertussis and atypical pathogens. Clin Microbiol Infect. 2012;18:138.

55. Koh MT, Liu CS, Chiu CH, et al. Under-recognized pertussis in adults from Asian countries: a crosssectional seroprevalence study in Malaysia, Taiwan and Thailand. Epidemiol Infect. 2016;144(6): 1192-200.

56. Son S, Thamlikitkul V, Chokephaibulkit K, et al. Prospective multinational serosurveillance study of Bordetella pertussis infection among 10- to 18-yearold Asian children and adolescents. Clin Microbiol Infect. 2019;25(2):250.e251-250.e257.

57. Aoyama T, Harashima M, Nishimura K, Saito Y. Outbreak of pertussis in highly immunized adolescents and its secondary spread to their families. Acta Paediatr Jpn. 1995;37(3):321-4.

58. Shimizu K, Ohtsuka M, Kikuchi K, Hiramatsu K. Nation-wide surveillance of pertussis in Japanese adults. Am J Respir Crit Care Med. 2010;181:A5483. https://doi.org/10.1164/ajrccm-conference.2010. 181.1_MeetingAbstracts.A5483.

59. Nogami H, Okada K, Iwanaga T. Clinical features of pertussis in adults. Am J Respir Crit Care Med. 2013;187:A3215.

60. Hara M, Fukuoka M, Tashiro K, et al. Pertussis outbreak in university students and evaluation of acellular pertussis vaccine effectiveness in Japan. BMC Infect Dis. 2015;15:45.

61. Kamano H, Mori T, Maeta $H$, et al. Analysis of Bordetella pertussis agglutinin titers during an outbreak of pertussis at a university in Japan. Jpn J Infect Dis. 2010;63(2):108-12.

62. Park S, Lee M-G, Lee KH, et al. A multicenter study of pertussis infection in adults with coughing in Korea: PCR-based study. Tuberculosis Respir Dis. 2012;73(5):266-72.

63. Park S, Lee SH, Seo K-H, et al. Epidemiological aspects of pertussis among adults and adolescents in a Korean outpatient setting: a multicenter, PCRbased study. J Korean Med Sci. 2014;29(9):1232-9.

64. Ryu S, Kim JJ, Chen M-Y, Jin H, Lee HK, Chun BC. Outbreak investigation of pertussis in an elementary school: a case-control study among vaccinated students. Clin Exp Vaccine Res. 2018;7(1):70-5.

65. Barkoff AM, Gröndahl-Yli-hannuksela K, He Q. Seroprevalence studies of pertussis: what have we learned from different immunized populations. Pathog Dis. 2015;73(7):ftv050.
66. Tondella ML, Carlone GM, Messonnier N, et al. International Bordetella pertussis assay standardization and harmonization meeting report. Centers for Disease Control and Prevention, Atlanta, Georgia, United States, 19-20 July 2007. Vaccine. 2009;27(6):803-14.

67. Guiso N, Berbers G, Fry NK, He Q, Riffelmann M, Wirsing von König $\mathrm{CH}$. What to do and what not to do in serological diagnosis of pertussis: recommendations from EU reference laboratories. Eur J Clin Microbiol Infect Dis. 2011;30(3):307-12.

68. Versteegh FG, Mertens PL, de Melker HE, Roord JJ, Schellekens JF, Teunis PF. Age-specific long-term course of IgG antibodies to pertussis toxin after symptomatic infection with Bordetella pertussis. Epidemiol Infect. 2005;133(4):737-48.

69. de Melker HE, Versteegh FG, Conyn-Van Spaendonck MA, et al. Specificity and sensitivity of high levels of immunoglobulin $G$ antibodies against pertussis toxin in a single serum sample for diagnosis of infection with Bordetella pertussis. J Clin Microbiol. 2000;38(2):800-6.

70. Guiso N, Liese J, Plotkin S. The Global Pertussis Initiative: meeting report from the fourth regional roundtable meeting, France, April 14-15, 2010. Hum Vaccin. 2011;7(4):481-8.

71. Guiso N, Wirsing von König $\mathrm{CH}$, Forsyth $\mathrm{K}$, Tan T, Plotkin SA. The Global Pertussis Initiative: report from a round table meeting to discuss the epidemiology and detection of pertussis, Paris, France, 11-12 January 2010. Vaccine. 2011;29(6):1115-21.

72. Takajo D, Nonoyama S. Severe pertussis in a young infant due to household transmission: the needs of pertussis vaccination boosters in Japan. Clin Case Rep. 2018;6(5):810-2.

73. Review Committee for Vaccination Guidelines (Japan). Vaccination and children's health. 2010. http://www.nakaharakodomo.com/_src/191/ vaccine.pdf.

74. Zhang Y, Bambrick H, Mengersen K, et al. Resurgence of pertussis infections in Shandong, China: space-time cluster and trend analysis. Am J Trop Med Hyg. 2019;100(6):1342-54.

75. Wu Y, Gao Y, Zhu B, et al. Antitoxins for diphtheria and tetanus decline more slowly after vaccination with DTwP than with DTaP: a study in a Chinese population. Vaccine. 2014;32(22):2570-3.

76. Zhang L, Wilson DP. Trends in notifiable infectious diseases in China: implications for surveillance and population health policy. PLoS ONE. 2012;7(2): e31076. 
77. Zhang Q, Zheng H, Liu M, et al. The seroepidemiology of immunoglobulin $G$ antibodies against pertussis toxin in China: a cross sectional study. BMC Infect Dis. 2012;12:138.

78. Li X, Chen M, Zhang T, Li J, Zeng Y, Lu L. Seroepidemiology of diphtheria and pertussis in Beijing, China: a cross-sectional study. Hum Vaccin Immunother. 2015;11(10):2434-9.

79. Taiwanese Centers for Disease Control. Pertussis. https://www.cdc.gov.tw/En/Category/ListContent/ bg0g_VU_Ysrgkes_KRUDgQ? uaid= tRFoq7YhMoz6moj0QsJcqA. Accessed Feb 2021.

80. World Health Organization. Diphtheria-tetanuspertussis (DTP3) immunization coverage. https:// www.who.int/gho/immunization/dtp3/en/. Accessed Aug 2020.

81. Chang IF, Lee PI, Lu CY, et al. Resurgence of pertussis in Taiwan during 2009-2015 and its impact on infants. J Microbiol Immunol Infect. 2019;52(4): 542-8. https://doi.org/10.1016/j.jmii.2019.06.002.

82. Korea Disease Control and Prevention Agency. National immunization program for children. https://www.cdc.go.kr/contents.es?mid= a30333000000 Accessed 26 Feb 2021.

83. Korean Centers for Disease Control and Prevention. Vaccine preventable infectious disease: epidemiology and management. 5th ed. Korean Centers for Disease Control and Prevention; 2017.

84. Mungall BA, Kim H, Oh KB. A systematic review of the burden of pertussis in South Korea. Human Vaccines Immunother. 2021; https://doi.org/10. 1080/21645515.2020.1844505.

85. Park S, Cho E. National infectious diseases surveillance data of South Korea. Epidemiol Health. 2014;36:e2014030.

86. Ministry of Health Singapore. National childhood immunisation schedule. https://www.moh.gov.sg/ resources-statistics/nationally-recommendedvaccines. Accessed Feb 2021.

87. Thain S, Tan S, Tagore S. Knowledge, perception and maternal immunisation practices of obstetricians in Singapore for the Tdap and influenza vaccines. Singapore Med J. 2019. https://doi.org/10. 11622/smedj.2019170.

88. National Center for Infectious Disease. Pertussis. https://www.ncid.sg/Health-Professionals/Diseasesand-Conditions/Pages/Pertussis.aspx. Accessed Feb 2021.
89. Guidelines. Guidelines for vaccinations of a normal child in India. Indian J Nephrol. 2016;26(Suppl 1): S5-6.

90. ThinkWell. Sustainable immunization financing in Asia Pacific. 2017. https://thinkwell.global/wpcontent/uploads/2018/09/Thailand-Country-Brief081618.pdf. Accessed Aug 2020.

91. Clark TA. Changing pertussis epidemiology: everything old is new again. J Infect Dis. 2014;209(7): 978-81.

92. Kilgore PE, Salim AM, Zervos MJ, Schmitt HJ. Pertussis: microbiology, disease, treatment, and prevention. Clin Microbiol Rev. 2016;29(3):449-86.

93. Amirthalingam G, Gupta S, Campbell H. Pertussis immunisation and control in England and Wales, 1957 to 2012: a historical review. Euro Surveill. 2013. https://doi.org/10.2807/1560-7917.ES2013. 18.38.20587.

94. Auger KA, Patrick SW, Davis MM. Infant hospitalizations for pertussis before and after Tdap recommendations for adolescents. Pediatrics. 2013;132(5):e1149-1155.

95. European Centers for Disease Prevention and Control. Pertussis. Annual epidemiological report for 2017. https://www.ecdc.europa.eu/en/publicationsdata/pertussis-annual-epidemiological-report-2017. Accessed August 2020.

96. Kamiya H, Otsuka N, Ando Y, et al. Transmission of Bordetella holmesii during pertussis outbreak, Japan. Emerg Infect Dis. 2012;18(7):1166-9.

97. Smith T, Rotondo J, Desai S, Deehan H. Pertussis surveillance in Canada: trends to 2012. Can Commun Dis Rep. 2014;40(3):21-30.

98. US Centers for Disease Control and Prevention. Pertussis (whooping cough). Fast Facts. https:// www.cdc.gov/pertussis/fast-facts.html. Accessed Sept 2020.

99. ACIP. Updated recommendations for use of tetanus toxoid, reduced diphtheria toxoid, and acellular pertussis vaccine (Tdap) in pregnant women-Advisory Committee on Immunization Practices (ACIP), 2012. MMWR Morb Mortal Wkly Rep. 2013;62(7): 131-5.

100. Amirthalingam G, Campbell H, Ribeiro S, et al. Sustained effectiveness of the maternal pertussis immunization program in England 3 years following introduction. Clin Infect Dis. 2016;63(suppl 4): S236-43.

101. Winter K, Nickell S, Powell M, Harriman K. Effectiveness of prenatal versus postpartum tetanus, 
diphtheria, and acellular pertussis vaccination in preventing infant pertussis. Clin Infect Dis. 2017;64(1):3-8.

102. Winter K, Zipprich J, Harriman K. Pertussis in California: a tale of 2 epidemics. Pediatr Infect Dis J. 2018;37(4):324-8.

103. Abu-Raya B, Bettinger JA, Vanderkooi OG, Vaudry W, Halperin SA, Sadarangani M. Burden of children hospitalized with pertussis in Canada in the acellular pertussis vaccine era, 1999-2015. J Pediatric Infect Dis Soc. 2020;9(2):118-27.

104. Abu-Raya B, Maertens K. Protection of the newborn through vaccination in pregnancy. NeoReviews. 2021;22(1):e25-39.

105. Abu-Raya B, Maertens K, Edwards KM, et al. Global perspectives on immunization during pregnancy and priorities for future research and development: an international consensus statement. Front Immunol. 2020;11:1282.

106. Amirthalingam G, Andrews N, Campbell H, et al. Effectiveness of maternal pertussis vaccination in England: an observational study. Lancet. 2014;384(9953):1521-8.

107. Forsyth K, Plotkin S, Tan T, Wirsing von König CH. Strategies to decrease pertussis transmission to infants. Pediatrics J. 2015;135(6):e1475-82.

108. Hong Kong Center for Health Protection. Recommendations on pertussis vaccination for pregnant women. 2019. https://www.chp.gov.hk/files/pdf/ letters_to_doctors_20190304.pdf. Accessed March 2021.

109. Dalby T, Andersen PH, Hoffmann S. Epidemiology of pertussis in Denmark, 1995 to 2013. Euro Surveill. 2016. https://doi.org/10.2807/1560-7917.ES. 2016.21.36.30334.

110. de Greeff SC, Mooi FR, Schellekens JFP, de Melker HE. Impact of acellular pertussis preschool booster vaccination on disease burden of pertussis in the Netherlands. Pediatr Infect Dis J. 2008;27(3): 218-23.

111. Broder KR, Cortese MM, Iskander JK, et al. Preventing tetanus, diphtheria, and pertussis among adolescents: use of tetanus toxoid, reduced diphtheria toxoid and acellular pertussis vaccines recommendations of the Advisory Committee on Immunization Practices (ACIP). MMWR Recommend Rep. 2006;55(Rr-3):1-34.
112. Zepp F, Heininger U, Mertsola J, et al. Rationale for pertussis booster vaccination throughout life in Europe. Lancet Infect Dis. 2011;11(7):557-70.

113. Quinn HE, McIntyre PB. The impact of adolescent pertussis immunization, 2004-2009: lessons from Australia. Bull World Health Organ. 2011;89(9): 666-74.

114. Skoff TH, Cohn AC, Clark TA, Messonnier NE, Martin SW. Early Impact of the US Tdap vaccination program on pertussis trends. Arch Pediatr Adolesc Med. 2012;166(4):344-9.

115. European Centers for Disease Prevention and Control. Pertussis: recommended vaccinations. https:// vaccine-schedule.ecdc.europa.eu/Scheduler/ ByDisease?SelectedDiseaseId=

$3 \&$ SelectedCountryIdByDisease $=-1$. Accessed August 2020.

116. Government of Cananda. Pertussis vaccine: Canadian immunization Schedule. https://www.canada. ca/en/public-health/services/publications/healthyliving/canadian-immunization-guide-part-4-activevaccines/page-15-pertussis-vaccine.html. Accessed March 2021.

117. Kim JH, Choi EH, Park SE, et al. Recommended immunization schedule for children and adolescents: Immunization Guideline (8th edition) released by the Korean Pediatric Society in 2015. Korean J Pediat. 2016;59(12):461-5.

118. Hong Kong Department of Health. Child health immunisation. 2020. https://www.fhs.gov.hk/ english/main_ser/child_health/child_health_ recommend.html. Accessed Sept 2020.

119. Japan Pediatric Society. 2018. https://www.jpeds.or. jp/uploads/files/20180801_JPS\%20Schedule\% 20English.pdf. Accessed Aug 2020.

120. Forsyth KD, Tan T, von König C-HW, Heininger U, Chitkara AJ, Plotkin S. Recommendations to control pertussis prioritized relative to economies: a Global Pertussis Initiative update. Vaccine. 2018;36(48): 7270-5.

121. Liu L, Oza S, Hogan D, et al. Global, regional, and national causes of under-5 mortality in 2000-15: an updated systematic analysis with implications for the Sustainable Development Goals. Lancet. 2016;388(10063):3027-35.

122. Wu D-X, Chen Q, Yao K-H, et al. Pertussis detection in children with cough of any duration. BMC Pediatr. 2019. https://doi.org/10.1186/s12887-0191615-3. 